\title{
All-Trans Retinoic Acid Increases DRP1 Levels and Promotes Mitochondrial Fission
}

\author{
Bojjibabu Chidipi ${ }^{1, *}{ }^{+}$, Syed Islamuddin Shah ${ }^{2,+}$, Michelle Reiser ${ }^{1}$, Manasa Kanithi ${ }^{1}$, Amanda Garces ${ }^{3}$, \\ Byeong J. Cha ${ }^{1,3}$, Ghanim Ullah ${ }^{2}$ iD and Sami F. Noujaim ${ }^{1}$
}

1 Department of Molecular Pharmacology and Physiology, Morsani College of Medicine, University of South Florida, Tampa, FL 33612, USA; mreiser1@usf.edu (M.R.); mkanithi@usf.edu (M.K.); bcha@usf.edu (B.J.C.); snoujaim@usf.edu (S.F.N.)

2 Department of Physics, University of South Florida, Tampa, FL 33620, USA; syedislamudd@usf.edu (S.I.S.); gullah@usf.edu (G.U.)

3 Lisa Muma Weitz Laboratory for Advanced Microscopy \& Cell Imaging, University of South Florida, Tampa, FL 33612, USA; agarces1@usf.edu

* Correspondence: chidipib@usf.edu

+ These authors have contributed equally to this work.

check for updates

Citation: Chidipi, B.; Shah, S.I.; Reiser, M.; Kanithi, M.; Garces, A.; Cha, B.J.; Ullah, G.; Noujaim, S.F. All-Trans Retinoic Acid Increases DRP1 Levels and Promotes Mitochondrial Fission. Cells 2021, 10, 1202. https://doi.org/10.3390/ cells10051202

Academic Editor: P.

Hemachandra Reddy

Received: 14 April 2021

Accepted: 10 May 2021

Published: 14 May 2021

Publisher's Note: MDPI stays neutral with regard to jurisdictional claims in published maps and institutional affiliations.

Copyright: (c) 2021 by the authors. Licensee MDPI, Basel, Switzerland. This article is an open access article distributed under the terms and conditions of the Creative Commons Attribution (CC BY) license (https:// creativecommons.org/licenses/by/ $4.0 /)$.

\begin{abstract}
In the heart, mitochondrial homeostasis is critical for sustaining normal function and optimal responses to metabolic and environmental stressors. Mitochondrial fusion and fission are thought to be necessary for maintaining a robust population of mitochondria, and disruptions in mitochondrial fission and/or fusion can lead to cellular dysfunction. The dynamin-related protein (DRP1) is an important mediator of mitochondrial fission. In this study, we investigated the direct effects of the micronutrient retinoid all-trans retinoic acid (ATRA) on the mitochondrial structure in vivo and in vitro using Western blot, confocal, and transmission electron microscopy, as well as mitochondrial network quantification using stochastic modeling. Our results showed that ATRA increases DRP1 protein levels, increases the localization of DRP1 to mitochondria in isolated mitochondrial preparations. Our results also suggested that ATRA remodels the mitochondrial ultrastructure where the mitochondrial area and perimeter were decreased and the circularity was increased. Microscopically, mitochondrial network remodeling is driven by an increased rate of fission over fusion events in ATRA, as suggested by our numerical modeling. In conclusion, ATRA results in a pharmacologically mediated increase in the DRP1 protein. It also results in the modulation of cardiac mitochondria by promoting fission events, altering the mitochondrial network, and modifying the ultrastructure of mitochondria in the heart.
\end{abstract}

Keywords: all-trans retinoic acid; DRP1; mitochondrial fusion; mitochondrial fission; mitochondrial network

\section{Introduction}

The mitochondrion is a dynamic organelle within the cell that produces energy as adenosine triphosphate (ATP) [1]. Sustaining functional mitochondria in optimal numbers and morphology is essential to cell survival and plays an important role in modulating a diversity of physiological processes. Mitochondrial self-regulatory mechanisms that include a dynamic interplay of the organelle's fusion, fission, mitophagy, and biogenesis are but a few factors shown to modulate mitochondrial quality control [2]. Mitochondrial fusion and fission are thought to be necessary for maintaining a robust population of mitochondria. Fusion is a dynamic event that leads to the merging of healthy individual mitochondria in order to form a new elongated organelle. Such an event ensures optimal cellular bioenergetics by producing adequate quantities of ATP to sustain cellular function [3]. Failure to carry out mitochondrial fusion begets impaired morphology and consequentially reduces the organelle's efficiency. On the other hand, mitochondrial fission supports a healthy mitochondrial structure by eliminating the damaged parts of a mitochondrion $[4,5]$. The 
balance of mitochondrial fusion and fission is dynamically regulated. Mitochondrial fusion is controlled by GTPases such as mitofusins (MFN1 and MFN2) on the outer mitochondrial membrane and optic atrophy 1 (OPA1) on the inner mitochondrial membrane. The fission events are controlled by dynamin-related protein (DRP1) and fission protein 1 (FIS1) [4,6-8]. The functional quality and architecture of the mitochondrial network is maintained through an appropriate equilibrium of fission and fusion events $[9,10]$. Damaged mitochondria are selectively removed by the process of mitophagy, which is regulated by the PTENinduced putative kinase 1 (PINK1)/Parkin pathway [11]. The E3 ubiquitin ligase, Parkin is available in the cytosol in normal conditions, but it is promptly translocated to the mitochondria upon the loss of mitochondrial membrane potential $(\Delta \psi \mathrm{m})[12,13]$. Alterations or mutations in fission and fusion events lead to mitochondrial dysfunction, irregular morphology, and cellular instability. Mitochondrial dysfunction has been implicated in several diseases including diabetes [14-16], retinal failure [17,18], liver failure [19], and neurological disorders [20-25].

Micronutrient retinoids such as all-trans retinoic acid (ATRA) can promote proper cellular differentiation, which makes them of interest for clinical applications [26-30]. ATRA is obtained in the form of carotenoids from plants or retinyl esters derived from diet and is stored in the liver, lungs, kidneys, and bone marrow [31]. ATRA is a bioactive derivative of Vitamin A and is involved in a broad spectrum of biological processes [32]. ATRA is thought to be important for neurogenesis, carcinogenesis, craniofacial morphogenesis, the formation of body axis and limbs, and the development of the lung, kidney, and eyes [33-37]. ATRA has been therapeutically used to treat acute promyelocytic leukemia [38], acne [39], and aging skin [40]. Additionally, studies are beginning to show that ATRA can modulate mitochondria. For instance, ATRA-treated adipocytes showed increased mitochondrial biogenesis by upregulating genes responsible for mitochondrial DNA replication and transcription [41]. Vantaggiato $C$ et al. found that retinoic acid increases neuronal differentiation from induced pluripotent stem cells by elevating the mitochondrial fission protein DRP1 [42]. However, there is no direct evidence of ATRA's effect on mitochondrial fusion and fission events.

In the heart, mitochondrial homeostasis is critical for sustaining normal function and optimal responses to metabolic or environmental stressors [43]. Disruptions in mitochondrial fission and/or fusion can lead to cellular dysfunction and apoptosis, important causes of cardiac myocyte death, particularly in heart failure [44-50]. In this study, we investigated the direct effects of ATRA on the mitochondrial network in cell culture and in murine hearts using Western blot, confocal, and transmission electron microscopy, as well as mitochondrial network quantification using agent-based stochastic modeling.

\section{Methods}

\subsection{Cell Culture}

Human embryonic kidney 293 (HEK293) and murine mouse atrial cell lines (HL-1) cells [51] were used in this study. HEK293 cells were cultured and maintained in Dulbecco's modified Eagle's cell culture medium (\#119955, Gibco, Gaithersburg, MD, USA) supplemented with 5\% FBS (\#26140095, Gibco, Gaithersburg, MD, USA). HL-1 cells were cultured in Claycomb medium (\#51800C, Sigma Aldrich, St. Louis, MO, USA) supplemented with 10\% FBS (\#TMS-016-B), 0.2 mM norepinephrine (\#A0937, Sigma Aldrich, St. Louis, MO, USA), and 5 mM glutamine (\#G7513, Sigma Aldrich, St. Louis, MO, USA) [52]. The dose-dependent effect of ATRA on mitochondrial fission and fusion were measured in HEK293 cells incubated with $0.1,0.5,1$, and $10 \mu \mathrm{M}$ ATRA for $24 \mathrm{~h}$. Time-dependent effects were measured at 6, 12, and $24 \mathrm{~h}$ in HEK293 cells treated with ATRA. HL-1 cardiomyocytes were incubated with $1 \mu \mathrm{M}$ ATRA for $24 \mathrm{~h}$ to analyze the mitochondrial network, fission, and fusion events. 


\subsection{Animals}

Animal experiments were approved by the IACUC at the University of South Florida. A total of six, 2-months-old, C57BL/6J mice of both sexes were used. Mice were housed in ventilated racks with ad libitum access to food and water. Three mice were treated with a $200 \mu \mathrm{L}$ of ATRA (\#R2625, Sigma Aldrich, St. Louis MO, USA), $(150 \mathrm{mg} / \mathrm{Kg}$, dissolved in corn oil) via i.p. injection. Three animals received i.p. injections of corn oil and served as controls. After $24 \mathrm{~h}$, the hearts were isolated via thoracotomy for the quantification of mitochondrial fission and fusion proteins using Western blot, morphology analysis using TEM, and the colocalization of mitochondrial fusion and fission proteins was conducted with confocal immunofluorescence.

\subsection{Western Blot}

To collect lysates from cell culture after treatment with ATRA, cells were rinsed with phosphate-buffered saline (PBS) and incubated on ice for $10 \mathrm{~min}$ in a RIPA lysis buffer (\#89900, Thermo Scientifics, Carlsbad, CA, USA) containing a protease inhibitor (\#P8340, Sigma Aldrich, St. Louis, MO, USA). Cells were collected into a $1.5 \mathrm{~mL}$ Eppendorf tube with a cell scraper and then triturated several times by passing through a $1 \mathrm{~mL}$ syringe. The total lysate was centrifuged at 12,000 rpm for $20 \mathrm{~min}$, and the supernatant was collected.

For collecting lysates from the ATRA-treated and control mice hearts, mice tissues were frozen to cryogenic temperatures in liquid nitrogen, and tissues were cryo-powdered with a Bessman tissue pulverizer (Spectrum Med, San Diego, CA, USA). Protein isolation was completed by adding $10 \mu \mathrm{L} / \mathrm{mg}$ of an RIPA lysis buffer to the cryopowder. The total lysate was centrifuged at 12,000 rpm for $20 \mathrm{~min}$, and the supernatant was collected.

Protein concentrations were determined with a BCA assay (Pierce ${ }^{\mathrm{TM}} \mathrm{BCA}$ Protein Assay Kit; \#23225, ThermoFisher, Carlsbad, CA, USA). Total protein $(10 \mu \mathrm{g})$ was loaded and separated by $4-20 \%$ premade SDS-PAGE gels (\#4568095, BioRad, Mini-PROTEAN TGX Stain-Free Precast Gels, Irvine, CA, USA), then transferred to a nitrocellulose membrane, and probed with an antibody against MFN1/2 $(1 \mu \mathrm{g} / \mathrm{mL}$; \#ab57602; abcam, Cambridge, MA, USA), FIS1 (1:1000; \#PA5-22142, Invitrogen, Carlsbad, CA, USA), OPA1 (2 $\mu \mathrm{g} / \mathrm{mL}$; \#NB110-55290, NOVUS Biotechnologies, Centennial, CO, USA), DRP1 (1:1000; \# \#8054, Cell Signaling, Danvers, MA, USA), and GAPDH (1:2000; \#sc-137179, Santa Cruz Biotechnology, Santa Cruz, CA, USA) at $4{ }^{\circ} \mathrm{C}$ overnight. After washing, the membrane was incubated with secondary fluorescent IRDye $800 \mathrm{CW}$ and $680 \mathrm{CW}$ goat anti-rabbit and anti-mouse antibodies (1:25,000; LiCOR, Nebraska, NE, USA) for $1 \mathrm{~h}$. The final images were detected with LiCOR Odyssey and protein bands were quantified using Imagestudio-LiCOR, software-2019.

\subsection{Isolation and Purification of Mitochondria from the Mouse Heart}

The isolation and purification of mitochondria were carried out at $4{ }^{\circ} \mathrm{C}$ for the entire $75 \mathrm{~min}$ procedure. Upon completing the procedure, the purified, isolated mitochondria were used within $2 \mathrm{~h}$. Isolation buffer A contained (in $\mathrm{mM}$ ) 70 sucrose, 210 mannitol, 1 EDTA- $\mathrm{Na}_{2}$, and 50 Tris- $\mathrm{HCl}$ at $\mathrm{pH}$ 7.4, and buffer B contained (in $\mathrm{mM}$ ) 250 sucrose, 10 HEPES-Na, and 1 EDTA-Na $\mathrm{N}_{2}$ at $\mathrm{pH}$ 7.4. The lower two-thirds of the ventricles were finely minced in $1 \mathrm{~mL}$ of buffer A, homogenized (10 rapid strokes) using a Dounce hand homogenizer (\#KT885300-0002, Kimble ${ }^{\mathrm{TM}}$ Kontes $^{\mathrm{TM}}$, Millville, NJ, USA), and transferred into a $1.5 \mathrm{~mL}$ Eppendorf tube. For $3 \mathrm{~min}$, the homogenate was centrifuged at $1300 \times \mathrm{g}$. The supernatant was collected and centrifuged for $10 \mathrm{~min}$ at $10,000 \times \mathrm{g}$. The crude mitochondria pellet was collected and suspended in a $55 \mu \mathrm{L}$ isolation buffer A. This crude mitochondrial preparation was then overlaid on $3 \mathrm{~mL}$ of 30\% (v/v) Percoll (\#GE17-0891-01, GE Healthcare, Danderyd, Sweden) in buffer B and centrifuged for $45 \mathrm{~min}$ at $50,000 \times g$. The resulting three distinct layers, M1, M2, and M3 [53,54], were isolated, transferred to $1 \mathrm{~mL}$ of isolation buffer $\mathrm{A}$, and further centrifuged for $5 \mathrm{~min}$ at $12,000 \times \mathrm{g}$. The mitochondrial pellet was carefully washed with $1 \mathrm{~mL}$ of isolation buffer $\mathrm{A}$ and then resuspended in $500 \mu \mathrm{L}$ of buffer A for confocal microscopy. 


\subsection{Confocal Microscopy}

HL-1 cardiomyocytes were cultured in an eight-well confocal chamber (\#155409, LABTEK, København, Copenhagen, Denmark) and treated with $1 \mu \mathrm{M}$ ATRA or vehicle for $24 \mathrm{~h}$. Cells were incubated with $50 \mathrm{nM}$ MitoTracker ${ }^{\mathrm{TM}}$ Red (\#M22425, Thermo Fisher Scientific, Carlsbad, CA, USA) for $30 \mathrm{~min}$ at $37^{\circ} \mathrm{C}$ and washed with freshly prepared FluoroBrite Dulbecco's modified Eagle's cell culture medium (\#119955, Gibco, Gaithersburg, MD, USA) supplemented with 10\% FBS (\#26140095, Gibco, MD, USA). A laser-scanning confocal microscope (Leica-SP8, Wetzlar, Germany) with a $63 \times$ oil objective was used to collect Z-stack images of cells. The mitochondrial network was quantified using MATLAB-based tools described below.

Immunofluorescence in isolated mitochondria was performed as described [55] In short, isolated mitochondria from both control and ATRA-treated mice were incubated with $500 \mu \mathrm{L}$ of buffer A containing $100 \mathrm{nM}$ MitoTracker ${ }^{\mathrm{TM}}$ Red for $1 \mathrm{~h}$ at $4{ }^{\circ} \mathrm{C}$. Mitochondria were then washed with PBS, followed by centrifugation at $12,000 \times g$ for $5 \mathrm{~min}$ and being plated dropwise onto coverslips precoated with $0.1 \%$ poly-l-lysine (\#P8920, Sigma-Aldrich, St. Louis, MO, USA) for $2 \mathrm{~h}$ at room temperature, and finally being washed with PBS. The attached mitochondria were fixed in $4 \%$ paraformaldehyde for $10 \mathrm{~min}$ at room temperature. Coverslips were gently washed three times for $5 \mathrm{~min}$ with PBS and permeabilized with $0.1 \%$ Triton X-100 in PBS for 10 min prior to being incubated with the primary antibody in PBS with $0.02 \%$ Tween (PBS-T) for $90 \mathrm{~min}$ at room temperature. The used antibodies were: rabbit monoclonal DRP1 antibody (1:1000; \#5391; Cell Signaling, Danvers, MA, USA) and rabbit monoclonal OPA1 antibody $(2 \mu \mathrm{g} / \mathrm{mL}$; \#NB110-55290, NOVUS Biotechnologies, Centennial, CO, USA). The primary antibody was removed by washing 3 times for $5 \mathrm{~min}$ with PBS-T. The preparations were then incubated with donkey anti-rabbit Alexa-488 conjugated antibody (1:10,000; \#A-21206, Life Technologies, CA, USA) on ice for $1 \mathrm{~h}$ in PBS-T. The coverslips were then mounted using VECTASHIELD ${ }^{\circledR}$ antifade mounting media (\#H1000, Maravai Life Sciences, San Diego, CA, USA) and imaged on a confocal microscope (Leica-SP8, Wetzlar, Germany) using a $63 \times$ oil objective. Immunolocalization was quantified between MitoTracker ${ }^{\mathrm{TM}}$ Red and DRP1 or OPA1 by analyzing Mender's (M1 and M2) coefficients using the Coloc 2 plugin Fiji version (2.1.0/1.53c) of Image (NIH, Bethesda, MD, USA) software (https:/ / fiji.sc/, accessed on 12 November 2020), as has been done before [56,57]. M1 and M2 are the summed intensities of colocalized green and red pixels, normalized by total green and red pixels; M1 measures the DRP1 or OPA1 green signal overlapped with MitoTracker ${ }^{\mathrm{TM}}$ Red signal and, M2 measures the MitoTracker ${ }^{\mathrm{TM}}$ Red signal overlapped with DRP1 or OPA1 green signal [58].

\subsection{Image Analysis}

In living cells, mitochondria exist as highly flexible and dynamic network architectures. Their ability to rapidly change from fully connected to fragmented structures driven by diverse cytosolic conditions and cell states is regulated by microscopic mitochondrial fission and fusion. Cells continuously change the rates of these processes in response to changing energy and metabolic demands to facilitate the redistribution of mitochondria (altering its topology) throughout the cell. Any dysregulation in fission and fusion rates result in the fragmentation of mitochondrial network and are linked to many diseases [59].

In graph theoretic terms, a mitochondrial network is described by nodes (mitochondrion) and edges (connections between individual mitochondria). Each node in the network can have zero (isolated mitochondrion, i.e., no connection with another mitochondrion), one (two connected mitochondria, like $\mathrm{o}-\mathrm{o}$ where o represents a mitochondrion), two (three mitochondria connected in a linear chain like $\mathrm{o}-\mathrm{O}-\mathrm{O}$ ), or three (four mitochondria connected in branched fashion, i.e., $\mathrm{O}-\mathrm{O}-\mathrm{O}$ with the mitochondrion in the middle connected to an additional mitochondrion) neighbors (mitochondria) termed as the degree $(\mathrm{k})$ of the node (Figure 6A). Our analysis showed that nodes with degree four (five mitochondria connected in branched fashion, i.e., $\mathrm{O}-\mathrm{O}-\mathrm{O}$ with the mitochondrion in the middle connected to two additional mitochondria) are rare and are, therefore, ignored. Depending on the pathophys- 
iological state of the cell, a mitochondrial network evolves into different topologies ranging from a fully fragmented state (a network comprising nodes of degree zero or one only) to a network with clusters of varying sizes that are made of loops and branches to a fully connected network of a single cluster. We refer to the largest cluster in the network (the network with the highest number of edges or connections) as a giant cluster and represent the number of edges in the giant cluster by $\mathrm{Ng}$. Thus, in the case of a fully connected network, the size of the giant cluster is the same as the whole network-that is $\mathrm{Ng}=\mathrm{N}$, where $\mathrm{N}$ is the total number of edges (connections) in the entire mitochondrial network in the cell. Under normal physiological conditions, a mitochondrial network comprises many (often interconnected) clusters with different sizes. Topologically, a mitochondrial network can be uniquely distinguished by various microscopic network parameters such as mean degree $<\mathrm{k}>$ (sum of degrees of all nodes in the network divided by $\mathrm{N}$ ), $\mathrm{N}_{\mathrm{g}}$, and $\mathrm{N}_{\mathrm{g}} / \mathrm{N}$, as well as features like the distributions of branch lengths (number of edges in a linear branch), loop sizes (number of edges in a cyclic loop, i.e., several mitochondria making a loop), and cluster sizes (number of edges in a cluster, which consist of both linear branches and cyclic loops but is disconnected from the rest of the network).

We used our previously curated pipeline of MATLAB-based tools to extract network parameters from experimental images of mitochondrial networks in control and ATRAtreated HL-1 cells using the following steps [60].

Step 1: We used the MATLAB function $i m 2 b w$ to generate a binary image (not shown) from the preprocessed gray scale image (not shown) of the original micrograph (left panels of Figure 5A,B) by applying an appropriate threshold intensity using MATLAB function graythresh.

Step 2: A single, one-pixel-thick skeleton image representing mitochondrial network (right panels of Figure 5A,B) was generated from the binary image (using bwmorph function from MATLAB) of step 1. Each pixel (representing a single mitochondrion in the right panels of Figure 5A,B) is colored based on whether it has one (red), two (green), or three (blue) neighbors (edges or degree).

Step 3: A skeletonized image from step 2 was converted to an undirected graph to extract network parameters $\langle\mathrm{k}\rangle, \mathrm{N}_{\mathrm{g}}, \mathrm{N}_{\mathrm{g}} / \mathrm{N}$, branch lengths, loop sizes, and cluster sizes (using the MATLAB function bwlabel).

\subsection{Modeling Mitochondrial Network}

While the confocal microscopy and TEM are useful in quantifying mitochondrial network parameters, estimating the microscopic rates of fission and fusion are beyond the scope of such analysis. Data-guided stochastic modeling can go a step further and provide a quantitative assessment of how the microscopic fission and fusion rates change in ATRA-treated cells in order to explain the experimental results.

To simulate the mitochondrial network, we used the model described by Sukhorukov et al. [61]. A simplistic mitochondrial network consists of two mitochondria (called a dimer) connected by an edge, referred to as $X_{1}$. In our simulations, a mitochondrial network grows/disintegrates through the two fusion/fission reactions (Figure 6A) given in Equations (1) and (2), respectively (see below). In the first (tip-to-tip) reaction (Figure 6A), the tip (one of the red nodes in Figure 6A) of a dimer, representing a single mitochondrion, fuses with the tip of another dimer to form a linear network of three mitochondria $\left(X_{2}\right)$ with an internal node (green node in Figure 6A) of degree 2. Note that the fusion of an $X_{1}$ species with the end-node of an $X_{2}$ species or the fusion of the end-nodes of two $X_{2}$ species results in a linear chain of more than three mitochondria with all internal nodes of degree 2 (that is, each internal mitochondrion is connected to one mitochondrion on the right side and one mitochondrion on the left side). In the second (tip-to-side) reaction (Figure 6A), the tip of a dimer $\left(X_{1}\right)$ fuses with the internal node (green node with degree 2 ) of $X_{2}$ to form a branched mitochondrial network $X_{3}$ with the internal node (blue node in Figure $6 \mathrm{~A}$ ) of degree 3 (that is, the mitochondrion in the middle is connected to three neighboring mitochondria). Note that the tip-to-side reaction can also occur due to the fusion of the end-node (mitochondrion 
at the end) of a linear chain (three or more mitochondrion connected in a linear chain) with the internal node (green) of $X_{2}$ species or another linear chain. Similarly, the end-node of a linear chain can react with the other end (tip-to-tip reaction) or the internal nodes (tip-to-side reaction) in the same chain to form cyclic loops. Generally, tip-to-side fusion reactions lead to clusters with loops and branches, whereas tip-to-tip fusion reactions tend to result in more linear chains. While fusion reactions are responsible for making bigger clusters, fission reactions (the reverse arrows in Equations (1) and (2)) disintegrate a given network. In the tip-to-tip fission reaction (Figure 6A and Equation (1) reverse arrow), $\mathrm{X}_{2}$ disintegrates into two $X_{1}$ species. In the tip-to-side fission reaction (Figure $6 \mathrm{~A}$ and Equation (2) reverse arrow), an $X_{3}$ node disintegrates to form one $X_{1}$ and one $X_{2}$ species. All the possible fusion and fission reactions described above can be represented by the following two reaction equations and are shown graphically in Figure 6A.

$$
\begin{aligned}
& X_{1}+X_{1} \underset{b_{1}}{\stackrel{a_{1}}{\rightarrow}} X_{2} \\
& X_{1}+X_{2} \stackrel{\stackrel{a_{2}}{\rightarrow}}{\overleftarrow{b_{2}}} X_{3}
\end{aligned}
$$

where $\mathrm{a}_{1}$ and $\mathrm{a}_{2}$ are the rates for the tip-to-tip and tip-to-side fusion reactions, respectively, and $b_{1}$ and $b_{2}$ are the rates for the respective fission reactions. As mentioned above, nodes of degree 4 are extremely rare and therefore ignored in the model [59]. Network edges connecting nodes define the minimal (indivisible) constituents of the organelle. Therefore, all parameters from our simulations were calculated in terms of number of edges in the network.

We implemented our mitochondrial network model as an agent-based model using the Gillespie algorithm [61]. Assuming that we wanted to model a mitochondrial network of size $\mathrm{N}$ ( $\mathrm{N}$ is generally determined by the size of the mitochondrial network retrieved by experimental micrographs, as described above in the Image Analysis section), each of our simulations started with $\mathrm{N}$ number of $\mathrm{X}_{1}$ species (Table 1). The network was allowed to stochastically evolve through a sequence of fusion and fission processes according to their propensities (probability of a reaction to occur) at a given time step. We ran the algorithm for $10 \times \mathrm{N}$ time steps to reach steady state and extracted various network features ( $<\mathrm{k}>, \mathrm{N}_{\mathrm{g}}$, branch lengths, etc.) at the end of the simulations using different graph and network algorithms in MATLAB's graph toolbox. Depending on the used fusion $\left(a_{1}\right.$ and $a_{2}$ ) and fission $\left(b_{1}\right.$ and $b_{2}$ ) rates (Figure 6A and Equations (1) and (2)), networks of varying properties ranging from one comprising interconnected linear chains and branched clusters to a single fully-connected giant cluster could be generated [61]. We searched for a network with experimentally observed properties $\left(\langle\mathrm{k}\rangle, \mathrm{N}_{\mathrm{g}}\right.$, branch length, etc.) $[59,61]$ by varying the ratio of fusion and fission processes using parameters $C_{1}=a_{1} / b_{1}$ and $C_{2}=a_{2} / b_{2}$ by, respectively, fixing $b_{1}=0.01$ and $b_{2}=(3 / 2)^{*} b_{1}$ and allowing $a_{1}$ and $a_{2}$ to vary. Assuming fixed $b_{1}$ and $b_{2}$ values, each value of $a_{1}$ and $a_{2}$ (and hence $C_{1}$ and $C_{2}$ ) generates a single mitochondrial network of a fixed topology (for a fixed size $\mathrm{N}$ of the initial network). This way, for every $\left(C_{1}\right.$ and $\left.C_{2}\right)$ pair in the $\left(C_{1}\right.$ and $\left.C_{2}\right)$ phase space, a mitochondrial network with different topologies can be generated. For every set of $C_{1}$ and $C_{2}$ values, we repeated the simulation 100 times, each time using a different random sequence for the stochastic fusion and fission processes. The network parameters/features averaged over all 100 runs are reported as the final results below (Figure 6). Larger values of $C_{1}$ and $C_{2}$ indicate more frequent tip-to-tip and tip-to-side fusion reactions, respectively, and vice versa. A very small value of $C_{2}$ (or $C_{1}$ ) results in a network mainly consisting of linear $\left(X_{2}\right.$ and $\left.X_{1}\right)$ networks (typical of a fragmented network) with small $<k>$ and $N_{g} / N$. A medium value of $C_{2}$ leads to a network having clusters with both branches and loops, whereas a large $C_{2}$ value results in a network having one giant cluster with large $<k>$ and $\mathrm{N}_{\mathrm{g}} / \mathrm{N}$ values where nearly all mitochondria are connected in a continuous network. 


\subsection{Transmission Electron Microscopy (TEM)}

C57Bl/6J mice were treated with ATRA ( $150 \mathrm{mg} / \mathrm{kg}$ in corn oil, i.p. injection). Control mice were treated with the same volume of corn oil. Twenty-four hours later, $4 \mathrm{~mm}^{3}$ of left ventricular walls were collected and trimmed into longitudinal blocks. After overnight storage in 2.5\% glutaraldehyde (\#16120, Electron Microscopy Sciences, Hatfield, PA, USA), the sections were postfixed in 1\% osmium tetroxide (\#19150, Electron Microscopy Sciences, PA, USA) for $1 \mathrm{~h}$. The tissue samples were dehydrated through a series of graded ethanol and embedded in Embed-812-resin (\#14120, Electron Microscopy Sciences, PA, USA). Semithin sections were cut at $1 \mu \mathrm{m}$, mounted on glass slides, and stained with $1 \%$ Toluidine Blue O (\#AAJ6601514, Fisher Scientific, Tracy, CA, USA). Ultrathin sections were cut at a thickness of $90 \mathrm{~nm}$ on an ultramicrotome (Ultracut E Richert-Jung, Vienna, Austria) and stained with $2 \%$ uranyl acetate (\#22400, Electron Microscopy Sciences, PA, USA) and lead citrate, (\#17800, Electron Microscopy Sciences, PA, USA) [62]. Selected ultrathin sections were imaged with TEM (JEOL; JEM-1400, Akishima, Tokyo, Japan) at 10,000X, 25,000X, and 50,000X magnification. Mitochondrial size (average area), number, and circularity were analyzed using Fiji version (2.1.0/1.53c) of Image (NIH, Bethesda, MD, USA) software (https: / / fiji.sc/, accessed on 12 November 2020). Mitochondrial number, area $\left(\mu \mathrm{m}^{2}\right)$, and perimeter $(\mu \mathrm{m})$ were analyzed at 10,000X magnification using the Image software (NIH, USA), as previously done by Demeter-Haludka V et al. [63]. Mitochondrial circularity was also computed as $4 \pi \times$ area $/$ perimeter $^{2}$ [64].

\subsection{Statistics}

Data are presented as mean \pm standard error of the mean. Unpaired 2-sample $t$-test or one sample $t$ - and Wilcoxon-test were used for statistical analysis.

\section{Results}

\subsection{All-Trans Retinoic Acid (ATRA) Upregulates the Fission Protein DRP1}

We tested the effects of ATRA on DRP1 and the fusion protein OPA1 levels in HEK293 cells using Western blot. ATRA was dissolved in DMSO, and cells were incubated with $0.1,0.5,1$, and $10 \mu \mathrm{M}$ ATRA or DMSO vehicle control for $24 \mathrm{~h}$. Figure $1 \mathrm{~A}$ shows that ATRA resulted in a dose-dependent increase in the levels of DRP1 normalized to GAPDH ( ${ }^{*} p<0.05$ vs. control; $n=4$ each). However, the levels of OPA1 were not significantly changed (Figure 1B). We also tested the time-dependent effect of ATRA in HEK293 cells. Cells were cultured with $0.5 \mu \mathrm{M}$ ATRA for 6,12 , and $24 \mathrm{~h}$. DRP1 levels were significantly increased after $24 \mathrm{~h}$ of treatment (data not shown). It was also found that $1 \mu \mathrm{M}$ of ATRA had no effect on mitochondrial fusion proteins MFN1/2 and mitochondrial fission protein FIS1 (Figure S1).

We then tested whether ATRA could lead to DRP1 upregulation in vivo. Two-monthsold C57BL/6J mice of both genders were used for ATRA $(n=3)$ and control $(n=3)$ treatments. ATRA $(150 \mathrm{mg} / \mathrm{Kg})$ was dissolved in in $200 \mu \mathrm{L}$ of corn oil and injected i.p. Control mice were treated with the same volume of corn oil $[65,66]$. After $24 \mathrm{~h}$, total lysates were obtained from both ATRA-treated and control mice hearts. A total of $10 \mu \mathrm{g}$ of proteins were used to assess DRP1 and OPA1 levels using Western blot. Similarly to the in vitro results, Figure 2 shows that ATRA significantly increased DRP1 protein levels (panel A top and panel B) but not OPA1 levels (panel A bottom and panel C) in mouse hearts $\left({ }^{*} p<0.05\right.$ vs. vehicle). ATRA did not have an effect on MFN1/2 and FIS1 (Figure S2). 

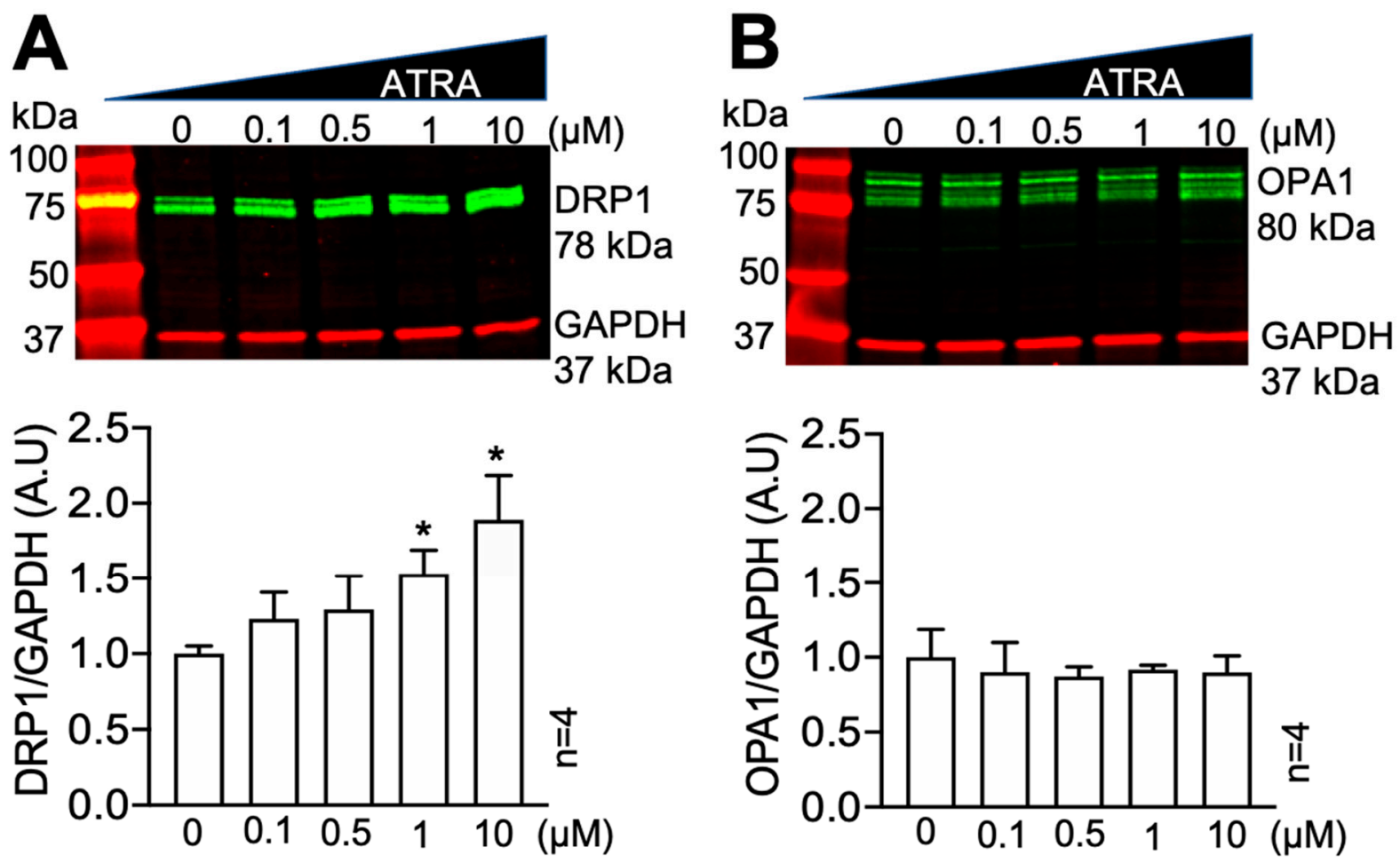

Figure 1. Dose-dependent effect of ATRA on DRP1 and OPA1. Western blot of DRP1 protein levels in HEK293 cells incubated with $0.1,0.5,1$, and $10 \mu \mathrm{M}$ ATRA for $24 \mathrm{~h}$, normalized to the levels of DMSO controls $(0 \mu \mathrm{M})$. (A) ATRA increased the levels of DRP1 in a dose-dependent manner $\left({ }^{*} p<0.05,1\right.$, and $10 \mu \mathrm{M}$ ATRA vs. DMSO control $(0 \mu \mathrm{M})$; One sample $t$ and Wilcoxon-test). (B) ATRA did not affect OPA1 levels.

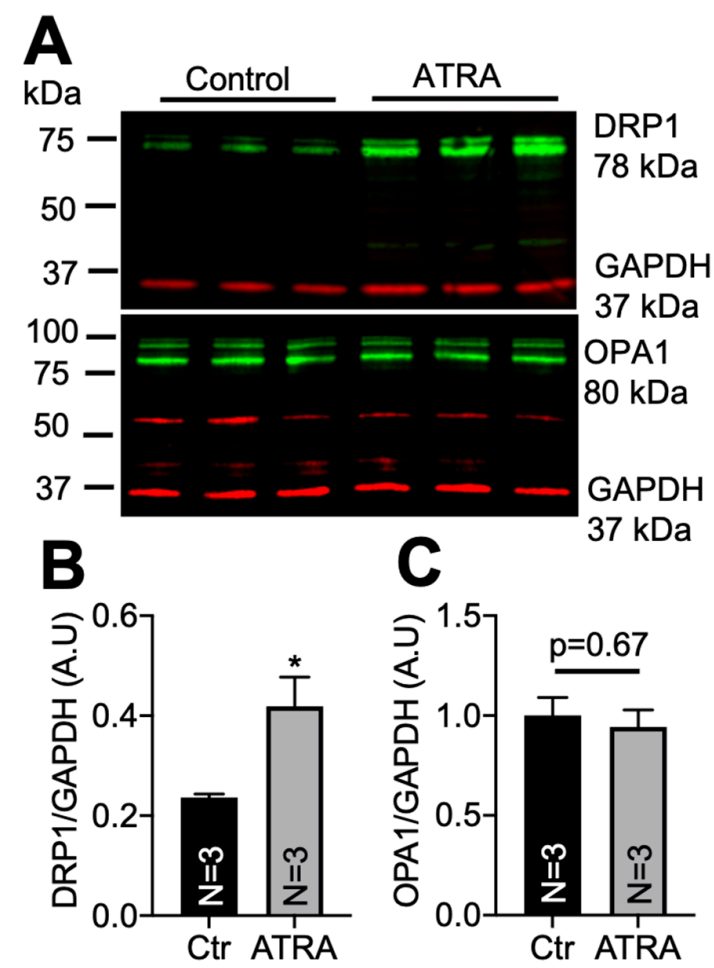

Figure 2. DRP1 and OPA1 levels in mouse hearts treated with an i.p. injection of ATRA or corn oil (vehicle control). (A) Western blots of DRP1 (upper panel) and OPA1 (lower panel). (B) DRP1 levels were significantly higher in ATRA-treated mice ( ${ }^{*} p<0.05$, vs. vehicle; unpaired 2 -sample $t$-test). (C) There was no effect of ATRA on OPA1. 


\subsection{Localization of DRP1 and OPA1 Levels in Purified Mitochondria from ATRA-Treated Mouse Hearts}

To further validate ATRA's effect on DRP1 and OPA1, we isolated live mitochondria from ATRA-treated and control mice ventricles using the sucrose and Percoll gradient method [53,54]. The purified and isolated mitochondrial fraction was co-labeled with MitoTracker ${ }^{\text {TM }}$ Red and antibodies against DRP1 or OPA1 (Figure 3). The colocalizations of DRP1 and OPA1 were analyzed by calculating Mender's coefficient using ImageJ (NIH, USA), as previously done by Strack $S$ et al. [67] in a similar experiment that showed DRP1dependent mitochondrial fragmentation, and our findings were consistent with those results [67]. ATRA caused a significant increase in DRP1 immunofluorescence colocalizing with MitoTracker ${ }^{\mathrm{TM}}$ Red signals compared to the control (Figure 3A,B). OPA1 showed no difference between the control and ATRA-treated groups (Figure $3 \mathrm{C}, \mathrm{D} ;{ }^{*} p<0.01 \mathrm{vs}$. control). In order to verify the integrity of our mitochondrial preparations, TEM was performed on a mitochondrial suspension.
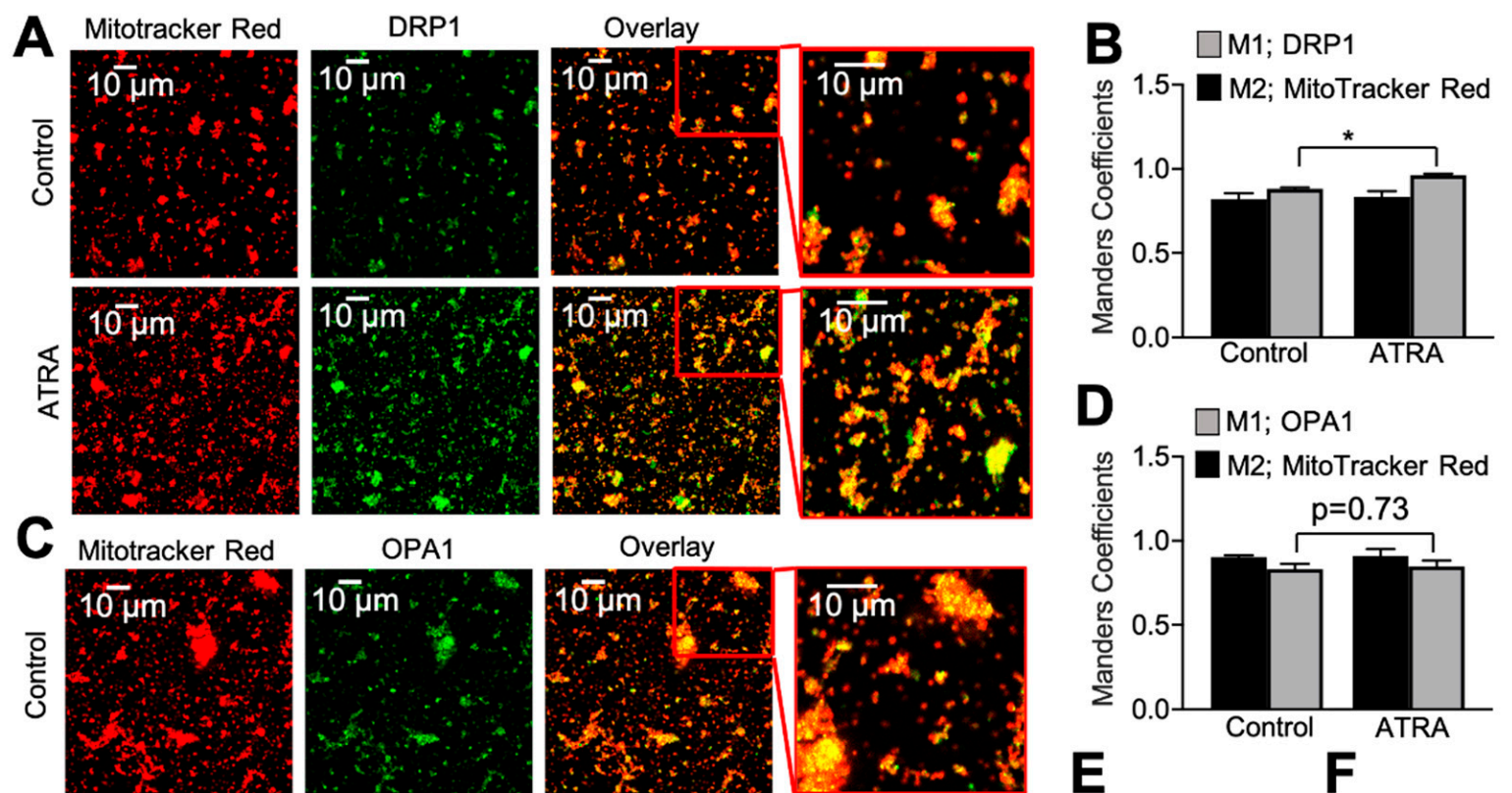

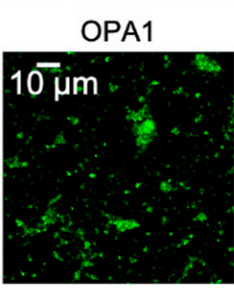

\begin{abstract}
Overlay
\end{abstract}
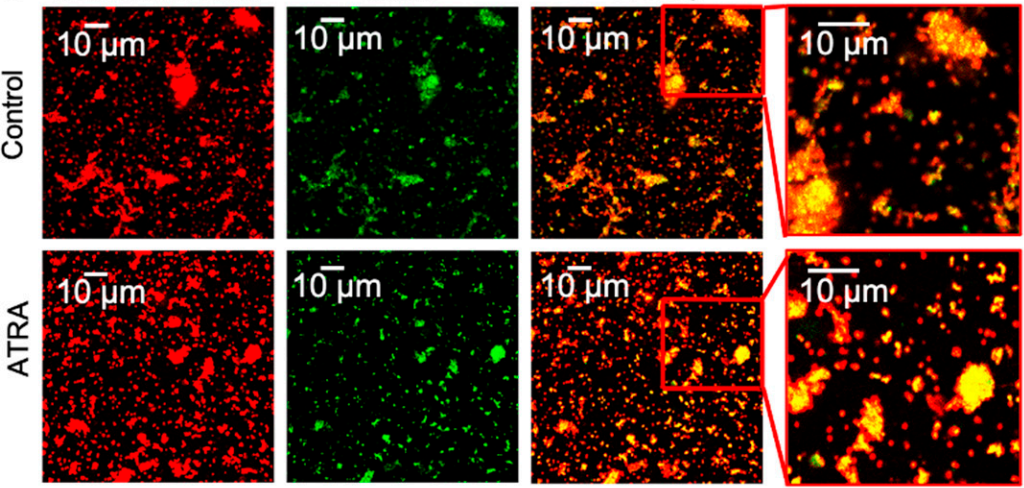
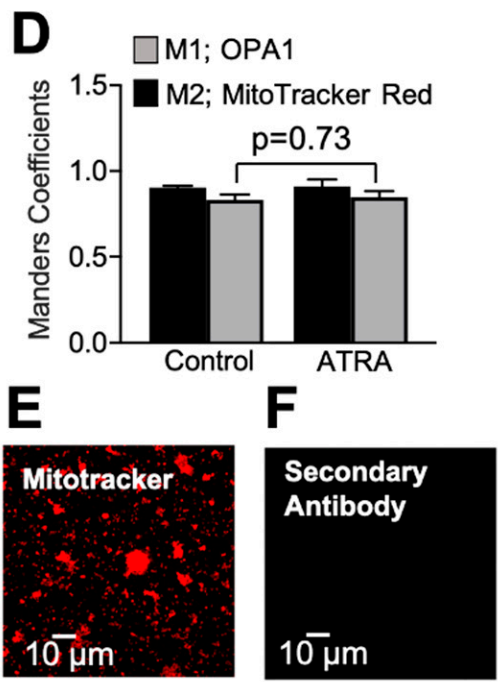

Figure 3. Quantification of mitochondrial localization of DRP1 and OPA1 by confocal microscopy. (A) Mitochondria were labeled with antibodies against DRP1 and (C) OPA1 in purified cardiac mitochondrial clusters from vehicle- (upper panels) and ATRA- (lower panels) treated mice. Red channel: MitoTracker ${ }^{\mathrm{TM}}$ Red. (B) and (D) Mander's coefficient of colocalization between MitoTracker ${ }^{\mathrm{TM}}$ Red (M2; black bars) and DRP1 (M1; gray bars) vs. OPA1 (M1; gray bars), respectively. In ATRA treatment, there was a significant increase in DRP1 colocalization with MitoTracker ${ }^{\mathrm{TM}}$ Red $\left({ }^{*} p<0.01\right.$, vs. vehicle; unpaired 2-sample $t$-test; $n=3$ mice; $n=12$ images) (B) but no change in OPA1 ( $n=3$ mice; $n=12$ images) (D). Mitochondria were loaded with MitoTracker ${ }^{\mathrm{TM}}$ Red (E) and labeled with secondary antibody alone (F).

\subsection{Mitochondrial Ultrastructural Changes in ATRA-Treated Mice}

We quantified mitochondrial morphology by TEM in the ATRA-treated mouse hearts versus controls. Figure $4 \mathrm{~A}$ shows micrographs from control and ATRA-treated ventricular tissue sections at $10,000 \times, 25,000 \times$, and 50,000 $\times$ magnification. We quantified mitochondrial area, perimeter, circularity, and number in hearts from three ATRA- and three vehicle-treated mice. ATRA significantly decreased the average mitochondrial area (Panel 
B; ${ }^{* * *} p<0.001$ vs. control) and perimeter (Panel C; ${ }^{* * *} p<0.001$ vs. control), and it significantly increased circularity (Panel D; $p<0.05 \mathrm{vs}$. control). The number of mitochondria tended to be increased by ATRA but did not reach significance (Panel E; ${ }^{*} p<0.05$ vs. control).
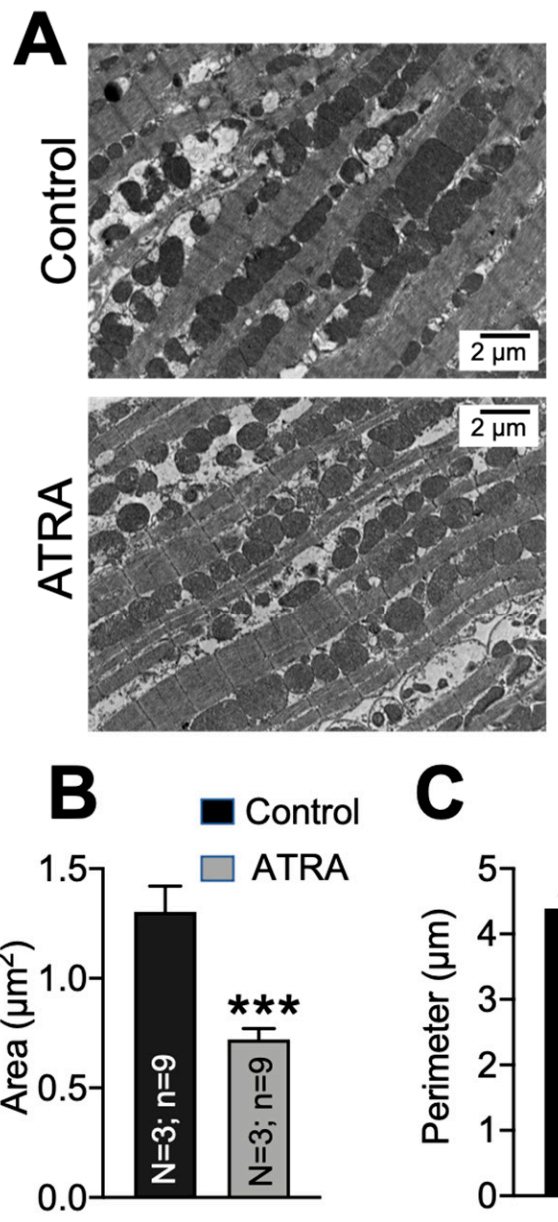
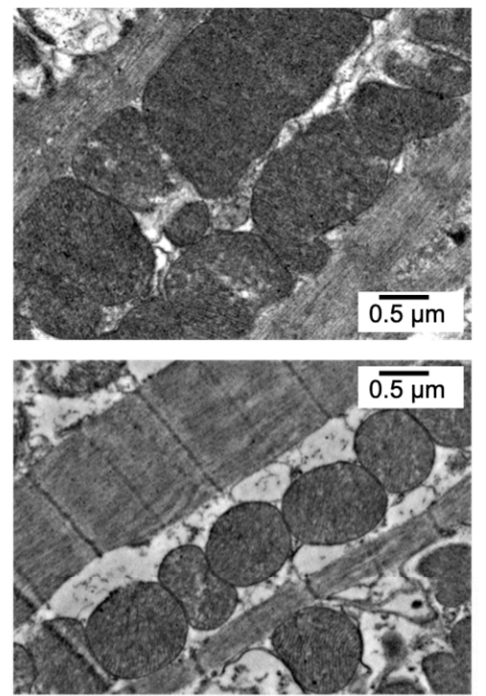

D
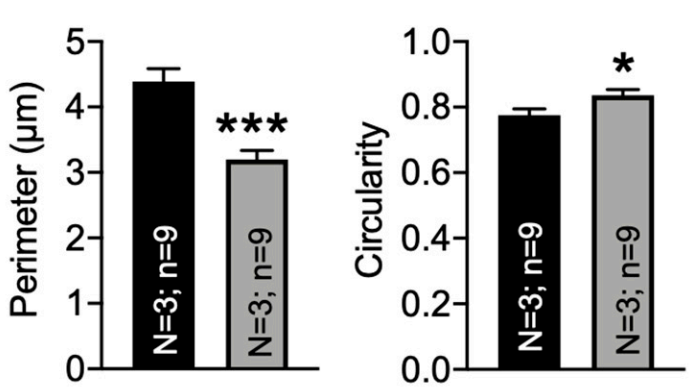

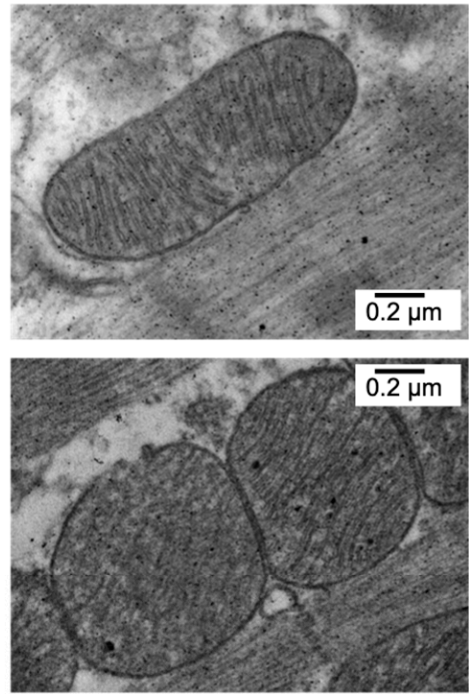

E

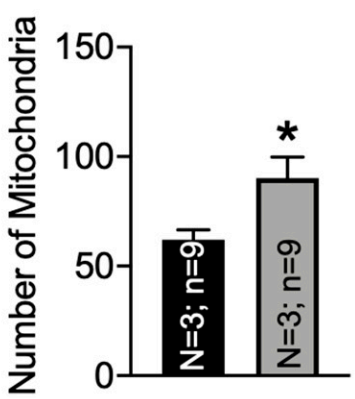

Figure 4. Effects of ATRA on mitochondrial ultrastructure in mice treated with ATRA versus control. (A) Representative electron micrographs from ATRA- and corn oil- (vehicle) treated mice at 10,000 $\times, 25,000 \times$, and 50,000 $\times$ magnification. Mitochondrial (B), average area (C), perimeter and (D) circularity, and (E) number of mitochondria per area. Mitochondrial area and perimeter were significantly decreased $(\mathbf{B}, \mathbf{C})$ and mitochondria were more circular in the ATRA-treated group (D) ${ }^{*} p<0.05,{ }^{* * *} p<0.001$, vs. vehicle; unpaired 2-sample $t$-test). $n=3$ hearts; $n=9$ micrographs each condition.

\subsection{Modeling Mitochondrial Networks in ATRA-Treated HL-1 Cells}

Graph theoretic network parameters have been widely used in computational modeling of mitochondrial fission and fusion [59,68-72]. Here, we applied our image processing toolkit and stochastic network simulation paradigm, as explained above, to process experimental micrographs and model mitochondrial networks in control and ATRA-treated HL-1 cells. HL-1 cell lines are mice atrial myocytes [52]. We chose HL-1 cells because the mitochondria are more abundant, representing approximately one-third of the mass of the heart ( $35 \%$ of the volume of adult cardiomyocytes), and play a critical role in maintaining cellular function. HL-1 cells were treated with vehicle or ATRA $(1 \mu \mathrm{M})$ for $24 \mathrm{~h}$. After $24 \mathrm{~h}$ of treatment, cells were stained with MitoTracker ${ }^{\mathrm{TM}}$ Red FM (50 nM; \#M22425, Thermo Fisher Scientific, CA, USA) for $30 \mathrm{~min}$, and Z-stack images were collected from live cells using a confocal microscope with a $63 x$-oil objective.

We analyzed Z-stack images from nine control cells and six ATRA-treated HL-1 cells. After preprocessing each experimental image, we generated a graph of the experimental mitochondrial image (Figure 5A,B) and retrieved microscopic network parameters such as 
$<\mathrm{k}>\mathrm{Ng}, \mathrm{Ng} / \mathrm{N}$, loop sizes, branch lengths, and cluster sizes for each case (Figure 5C-I). We found that loop sizes, branch lengths, and cluster sizes were all shifted to smaller values in the ATRA-treated cells (blue) than in the control cells (red), suggesting a relative increase in fission in ATRA-treated cells (Figure 5C-E). Similarly, microscopic network parameters including mean degree, average cluster size, largest cluster size $(\mathrm{Ng})$, and largest cluster size normalized with respect to the total network size $(\mathrm{Ng} / \mathrm{N})$ were reduced in ATRAtreated cells (gray bars) compared to control cells (black bars) (Figure 5G-I). However, the mean degree $(<\mathrm{k}>)$ and average cluster size were significantly decreased in ATRA-treated HL- 1 cells compared to the control. The largest clusters size $(\mathrm{Ng})$ (Figure $5 \mathrm{H} ; p=0.19$ vs. control) and the largest cluster size normalized with the total network $(\mathrm{Ng} / \mathrm{N})$ tended to decrease but did not reach statistical significance.

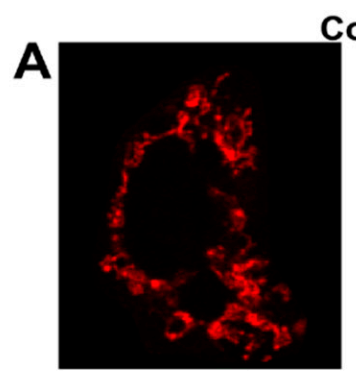

Control
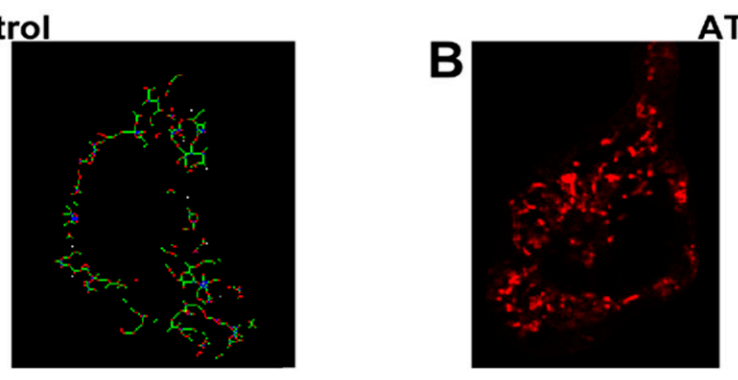

ATRA
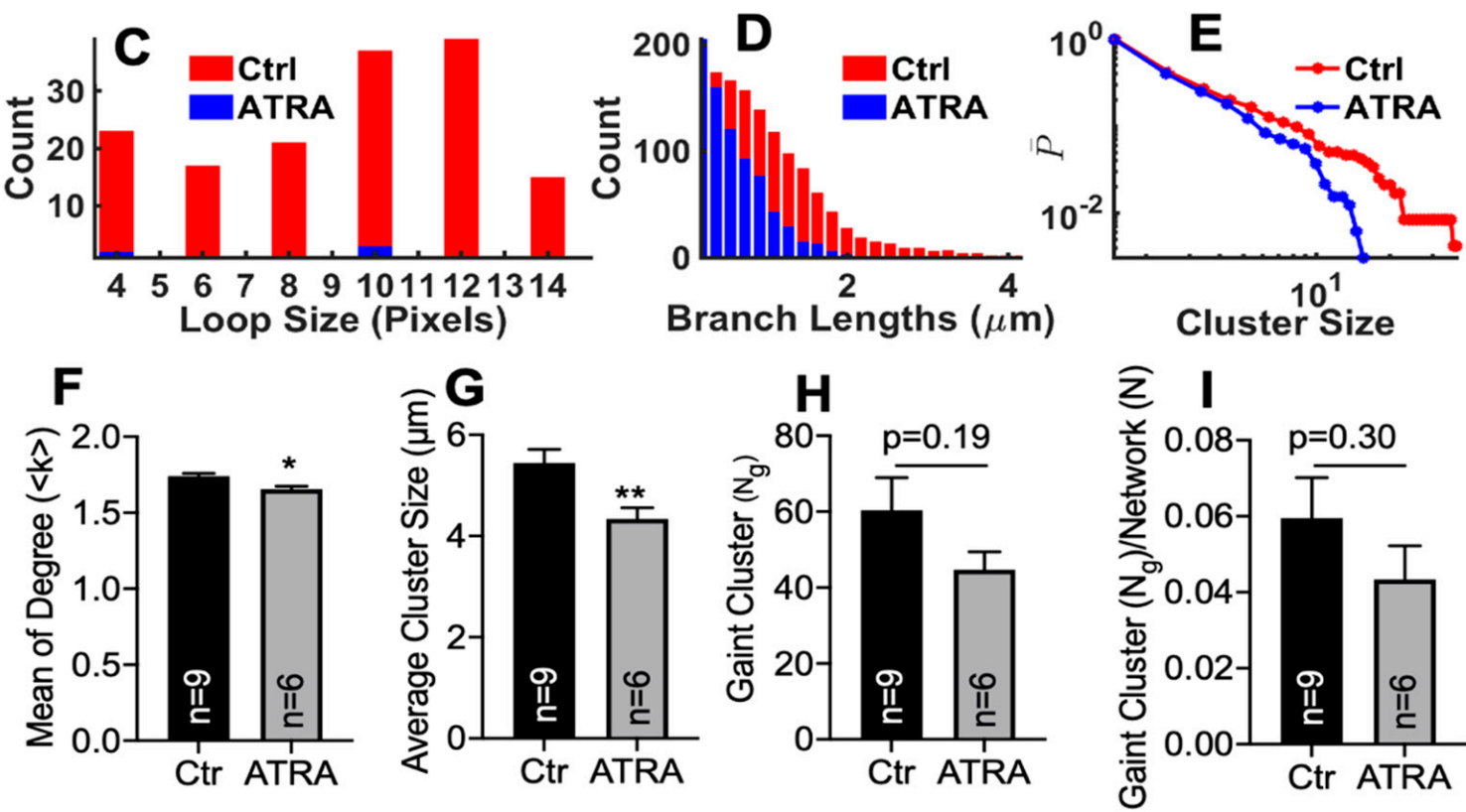

Figure 5. Microscopic properties of the mitochondrial network in control and ATRA-treated HL-1 cells. Representative confocal images of the mitochondrial network in (A) control and (B) ATRA-treated cells from experiments (left panels) and the network retrieved using image processing (right panels). Distributions of loop sizes (C), branch lengths (D), and cluster sizes (E) (cumulative probability) for control (red) and ATRA-treated cells (blue). Mean degree (F), average cluster size (G), giant cluster $(\mathbf{H})$, and the giant cluster normalized to the total network size $(\mathbf{I}) .{ }^{*} p<0.05,{ }^{* *} p<0.01$, vs. control; unpaired 2-sample $t$-test.

After identifying the various network parameters from experimental images, we performed stochastic simulations (Figure 6A) to identify microscopic fusion and fission rates responsible for the network topology in the control and ATRA-treated cells. For a mitochondrial network of size $\mathrm{N}$ (approximated from experiential micrograph), we started with $N$ number of $X_{1}$ species and ran the simulations with a given combination of $C_{1}$ and $C_{2}$ values. Over time, the network evolved such that it had different numbers of $X_{1}, X_{2}$, and $X_{3}$ species at given iteration numbers. A typical evolution of the network in terms of the distribution of $X_{1}, X_{2}$, and $X_{3}$ species as the iteration number increases is shown 
in Figure $6 \mathrm{~B}$ for two different combinations of $\mathrm{C}_{1}$ and $\mathrm{C}_{2}$ values. Simulations were run until a steady state was reached, where the number of $X_{1}, X_{2}$, and $X_{3}$ species were not changing anymore (Figure 6B), and parameters were retrieved from the resulting network as reported below.

A (i) tip-to-tip fusion reaction

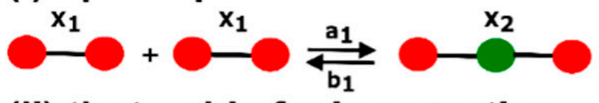

(ii) tip-to-side fusion reaction

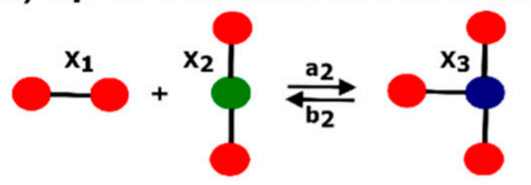

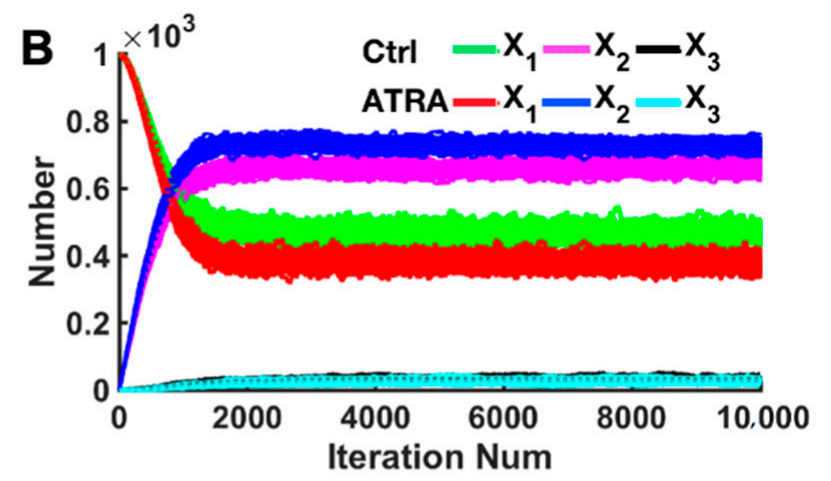
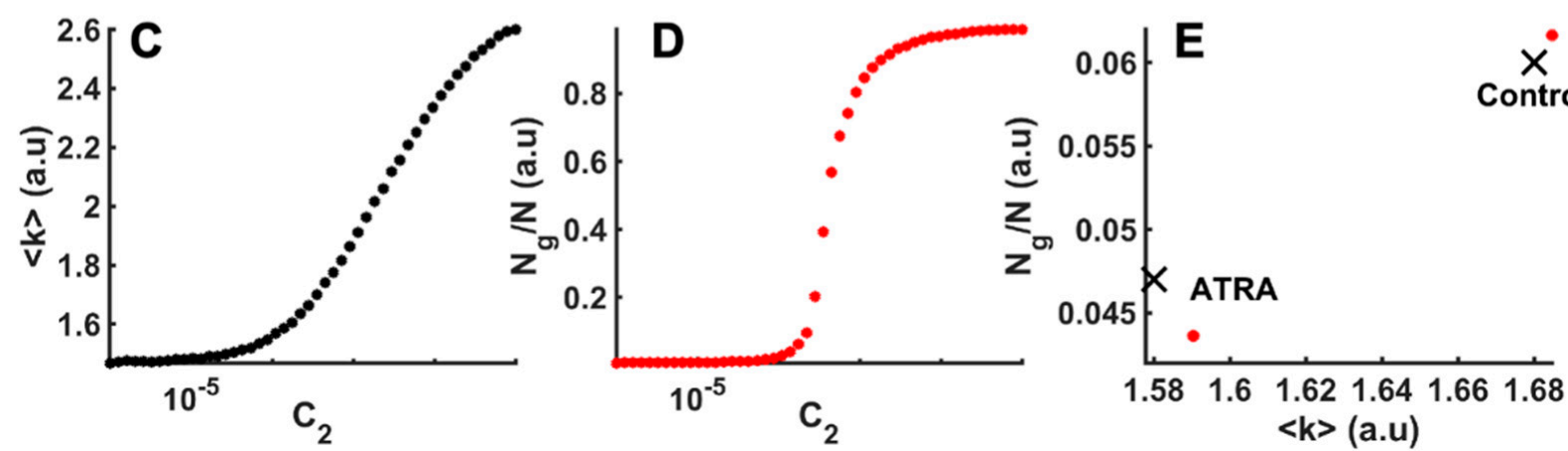

Figure 6. Estimating relative fusion and fission rates using agent-based model. (A) Model scheme representing the tip-to-tip fusion of two $X_{1}$ nodes into $X_{2}$. Tip-to-side fusion of one $X_{1}$ node with one $X_{2}$ node to form one $X_{3}$ node, as well as the corresponding fission processes. (B) The number of vehicle (control), or ATRA $X_{1}, X_{2}$, and $X_{3}$ species from the model as functions of the number of iterations using the $C_{1}$ and $C_{2}$ values given in Table 1 . Model results for mean degree (C) and $\mathrm{N}_{\mathrm{g}} / \mathrm{N}(\mathrm{D})$ as functions of $\mathrm{C}_{2}$ at fixed $\mathrm{C}_{1}=0.0007$ and $n=3000$. (E) Comparison of $\mathrm{N}_{\mathrm{g}} / \mathrm{N}$ versus $<\mathrm{k}>$ values obtained from experiment (red bullets) and simulation (black crosses) in control and ATRA-treated cells.

The above approach allowed us to scan the $\left(C_{1}\right.$ and $\left.C_{2}\right)$ phase space and find the $C_{1}$ and $\mathrm{C}_{2}$ values that resulted in a mitochondrial network with the topology and microscopic parameters, as observed in the control and ATRA-treated cells. As an example, results from simulations (for a network of size $n=3000)$ at fixed $C_{1}=0.0007\left(a_{1}=0.000007, \mathrm{~b}_{1}=0.01\right.$, and $\left.b_{2}=(3 / 2)^{*} b_{1}\right)$ but varying $C_{2}$ (tip-to-side fusion reaction rate $a_{2}$ ) are shown in Figure $6 C, D$. Increasing the tip-to-side fusion reaction resulted in networks with larger branched clusters with higher mean degree $\left\langle\mathrm{k}>, \mathrm{N}_{\mathrm{g}} / \mathrm{N}\right.$, cluster sizes, etc. Figure $6 \mathrm{C}$, D clearly show that $<\mathrm{k}>$ and $\mathrm{N}_{\mathrm{g}} / \mathrm{N}$ both increased as we increased $\mathrm{C}_{2}$ (and hence $\mathrm{a}_{2}$ ). These simulations were repeated until we found a combination of $C_{1}$ and $C_{2}$ values that resulted in a network with $<\mathrm{k}>$ and $\mathrm{N}_{\mathrm{g}} / \mathrm{N}$ values that matched with those experimentally observed within certain tolerance [60].

In Figure $6 \mathrm{E}$, we show the $\mathrm{N}_{\mathrm{g}} / \mathrm{N}$ vs. $<\mathrm{k}>$ values of mitochondrial network in experimental images from one control and one ATRA-treated cell (red bullets), as well as the fits from the model (black crosses). Both observed and simulated networks showed a significant shift in $\mathrm{N}_{\mathrm{g}} / \mathrm{N}$ and $<\mathrm{k}>$ towards smaller values in ATRA-treated cells compared to the control cells. We remark that the fit to the data could be further improved by decreasing the increment by which we changed $C_{1}$ and $C_{2}$ values while scanning the parameter space. However, decreasing this increment exponentially increased the computational time. Thus, a compromise between the accuracy of the fit and the computational time was made. Table 1 lists the values of $<\mathrm{k}>$ and $\mathrm{N}_{\mathrm{g}} / \mathrm{N}$ obtained from our experiments and 
simulations. The $\mathrm{C}_{1}$ and $\mathrm{C}_{2}$ values resulting in $<\mathrm{k}>$ and $\mathrm{N}_{\mathrm{g}} / \mathrm{N}$ values are also reported in Table 1 , indicating a clear decrease in the ratio between tip-to-tip fusion and fission rates $\left(a_{1}\right.$ and $b_{1}$ in $C_{1}=a_{1} / b_{1}$ ). In fact, these results indicated that the ratio between tip-to-tip fusion and fission rates was about $83 \%$ smaller in ATRA-treated cells compared to the control cells. We also report the fraction of $X_{1}, X_{2}$, and $X_{3}$ species in the network at steady state in Table 2 for control and ATRA-affected cells. We found a smaller number of X3 species in ATRA-treated cells, which further confirmed the greater mitochondrial fragmentation in ATRA cells compared to control cells. In Figure 4E, the number of mitochondria is shown to have been increased by ATRA treatment (Panel E, ${ }^{*} p<0.05$ vs. control). Such an increase could be attributed to the increase in fragmentation or fission (lower X3), as suggested by the simulations. Similarly, in Figure 5, it is seen that ATRA decreased the mitochondrial loop size (i.e., decreased number of mitochondria in a loop), branch length (number of edges in a linear branch), and mitochondrial cluster size (number of edges in a cluster, which consists of both linear branches and cyclic loops but is disconnected from the rest of the network). The simulations of Figure 6 assess the structure of the mitochondrial network (regarding whether the network was fragmented) regardless of the network size. That is, Figure 6 gives a measure of how fragmented the mitochondrial network that was imaged and quantified in Figure 5 was and what the microscopic fusion and fission rates that could explain such fragmentation were. The simulations indicated that the ratio between tip-to-tip fusion and fission rates was about $83 \%$ smaller in ATRA-treated cells compared to control cells.

Table 1. Comparison of microscopic parameters of mitochondrial network obtained from experiments (Exp) and simulations (Theory). Mean degree (columns 2 and 3) and $\mathrm{Ng} / \mathrm{N}$ (columns 4 and 5) from experiment and theory. Columns 6 and 7 list the values of $\mathrm{C} 1$ (tip-to-tip fusion/fission ratio) and C2 (tip-to-side fusion/fission ratio) obtained by fitting the model to the data. Notice that C1 decreased by $83 \%$ in ATRA-treated cells compared to control.

\begin{tabular}{clccccc}
\hline \multirow{2}{*}{ Condition } & \multicolumn{2}{l}{ Mean Degree $<$ k $>$} & \multicolumn{2}{c}{$\mathbf{N}_{\mathbf{g}} / \mathbf{N}$} & \multirow{2}{*}{$\mathbf{C}_{\mathbf{1}}$} & $\mathbf{C}_{\mathbf{2}}$ \\
& Exp & Theory & Exp & Theory & & \\
\hline Ctrl & 1.68 & 1.68 & 0.060 & 0.062 & $5.5 \times 10^{-3}$ & $2.0 \times 10^{-4}$ \\
\hline ATRA & 1.58 & 1.59 & 0.047 & 0.045 & $3.0 \times 10^{-3}$ & $2.0 \times 10^{-4}$ \\
\hline
\end{tabular}

Table 2. The fractions of $\mathrm{X} 1, \mathrm{X} 2$, and $\mathrm{X} 3$ species at steady state using $\mathrm{C} 1$ and $\mathrm{C} 2$ values estimated for control and ATRA-treated cells. Notice that X1, X2, and X3 decreased by $25 \%$, increased by $17 \%$, and decreased by $10 \%$, respectively, in ATRA-treated cells compared to control.

\begin{tabular}{cccc}
\hline Condition & $\mathbf{X}_{\mathbf{1}}$ & $\mathbf{X}_{\mathbf{2}}$ & $\mathbf{X}_{\mathbf{3}}$ \\
\hline Ctrl & 0.436 & 0.541 & 0.023 \\
\hline ATRA & 0.349 & 0.631 & 0.020 \\
\hline
\end{tabular}

\section{Discussion}

Mitochondrial fission is a dynamic event that is regulated by proteins such as DRP1 and FIS1. Normal fission is necessary for maintaining cellular function. The fission machinery is vital for tissue development. For instance, DRP1 knockout in mice is embryonically lethal [73], and aging leads to decreased DRP1 protein levels in cardiac and skeletal muscles [74]. Previously, Vantaggiato $C$ et al. tested the effects of ATRA in embryonic carcinoma cell lines (P19 cells) [43]. P19 cells were differentiated into neurons and glial cells in the presence of $5 \mu \mathrm{M}$ ATRA for 14 days. It was found that DRP1 was upregulated during the neuronal differentiation by ATRA [43]. However, it is not known whether ATRA can also upregulate cardiac DRP1. Here, we tested in vivo and in vitro whether ATRA affects DRP1 in the heart. Our results suggested that ATRA elevates DRP1 levels and elicits mitochondrial network remodeling by increasing mitochondrial fission, as suggested by 
our numerical modeling. Our results showed that ATRA dose-dependently increased DRP1 levels, decreased mitochondrial area and perimeter, and increased circularity.

Mitochondria are central players in cell metabolism and bioenergetics, and their dysfunction could underlie disease processes [75]. Robust mitochondrial fission and fusion events sustain an efficient and healthy mitochondrial matrix [73]. Therefore, the proteins and factors involved in mitochondrial fission-fusion are being explored as therapeutical targets $[74,76]$. The modulations of these events through post-translational modifications, cofactors, and externally applied agents could result in improving mitochondrial biogenesis and the organelle's network integrity.

DRP1 is an integral mitochondrial fission factor. Transcriptional $[77,78]$ and posttranslational modifications [79] are key mechanisms regulating and controlling DRP1 levels. The loss or dysfunction of DRP1 has been shown to be lethal during embryonic development [80]. DRP1 downregulation has been implicated in apoptosis [81] and mitochondrial autophagy [82], causing increased oxidative stress levels and leading to a cascade of inefficient and detrimental cellular processes.

It has been proposed that promoting a balanced and healthy mitochondrial network by targeting DRP1 could be a useful approach that improves cellular energetics and metabolism in different pathologies [83]. Studies used the genetic overexpression of DRP1 as a way to increase mitochondrial fission [83-86]. Here, we evaluated the effect of pharmacologically mediated DRP1 increase via ATRA. Our experiments in HEK293 and HL-1 cell lines, as well as in mice, suggested that ATRA results in increased DRP1 levels and mitochondrial remodeling.

Mitochondrial network integrity is balanced by fission and fusion processes [87], and a healthy mitochondrial network is essential for cellular function [88]. Our mitochondrial network analysis showed that, compared to vehicle control-treated cells, ATRA-treated HL-1 cells possess a lower mean degree $(<\mathrm{k}>), \mathrm{N}_{\mathrm{g}} / \mathrm{N}$, smaller loops/cluster sizes, and smaller branch lengths representative of fragmented networks. Our stochastic simulations further suggested that at the microscopic level, mitochondrial fusion and fission dynamics are shifted by ATRA. Specifically, an upregulated tip-to-tip fission reaction could explain the mitochondrial network analysis results.

Various findings have shown that DRP1-mediated processes are crucial for maintaining normal cardiac function $[89,90]$. It was shown that DRP1 inhibition decreased cell death in HL-1 after simulated ischemia/reperfusion [91]. Ashrafian et al. found that alteration in the DRP1 gene leads to the enlargement of ventricular thickness, contractility, and increased fibrosis in transgenic mice [92]. Tang et al. found a lower level of DRP1 in chronically hypertrophied, hypertensive rat hearts [93], but the pro-hypertrophic neurohormone norepinephrine was found to increase DRP1 levels in cardiomyocytes [94]. Additionally, it was shown that DRP1 downregulation resulted in mitochondrial elongation, impaired mitochondria aggregation, and accelerated apoptosis in cardiomyocytes [89]. Several studies have shown that the loss of DRP1 enlarges the heart size by possibly decreasing autophagy and mitophagy [95-97].

To our knowledge, there is no known pathway directly linking ATRA to increased DRP1 levels. It could be possible that ATRA induces epigenetic modifications through retinoic acid receptor-dependent mechanisms that ultimately modulate DRP1 expression [98].

Our results indicated that while ATRA treatment increased DRP1 levels, it did not alter the levels of the mitochondrial fusion protein OPA1. OPA1 is essential for maintaining normal fusion, as hampering mitochondrial fusion can harm the cristae structure and inner mitochondrial membrane integrity, leading to the release of cytochrome c $[99,100]$.

\section{Limitations}

The accuracy of the estimated fusion rates, fission rates, and mitochondrial network statistics using the image processing and modeling approaches used in this study relied on the confocal imaging of the mitochondrial network. The construction of the digitized 
mitochondrial network from experimental images relied on image segmentation steps such as image smoothing, threshold selection, background noise removal, thinning, and skeletonizing. All these parameters could potentially affect size, structure, and microscopic parameters such as mean network degree $<\mathrm{k}>$, giant cluster size $\mathrm{Ng}, \mathrm{Ng} / \mathrm{N}$ ratio, the distribution of cluster sizes, branch lengths, and cell cycles of the identified network. The final network generated by the model was also sensitive to the intrinsic stochastic nature of the fission and fusion processes and could vary depending on the duration for which a simulation was run and the number of times a simulation with a given parameter set was repeated. We overcame these limitations by performing long simulations to ensure that an actual steady state was reached and performing hundreds of repetitions for each control and ATRA-treated cell. The total mitochondrial volume in ATRA versus vehicle control treatment was not studied. Our imaging of the mitochondrial network in HEK293 cells did not result in robust images that could be used for analysis, as done in Figure 5. Therefore, only HL-1 cells were used.

\section{Conclusions}

Our findings suggested that ATRA elevates DRP1 levels without changing those of OPA1, promotes fission events, alters the mitochondrial network, and modifies the ultrastructure of mitochondria in the heart. Future investigations should assess whether ATRA could play a role in cardiac protection by eliminating the damaged parts of mitochondria through a DRP1-mediated mitochondrial fission process.

Supplementary Materials: The following are available online at https:/ / www.mdpi.com/article/10 .3390 / cells10051202/s1, Figure S1. MFN1/2 and FIS1 levels in HEK293 cells treated with ATRA or DMSO (vehicle control). Figure S2. MFN1/2 and FIS1 levels in mouse hearts treated with ATRA or corn oil (vehicle control) via i.p. injection.

Author Contributions: Conceptualization, B.C., and S.F.N.; experimental investigation, B.C., M.R., S.I.S., G.U., M.K., B.J.C., A.G., and S.F.N.; analysis, B.J.C., S.I.S., M.R., G.U., and S.F.N.; manuscript preparation, B.J.C., M.R., M.K., G.U., and S.F.N. All authors have read and agreed to the published version of the manuscript.

Funding: This research was funded by AHA postdoc grant (19POST34450203) to B.C, NIH-R01 (AG053988) to G.U, and NIH-R01 (HL129136) to S.F.N.

Institutional Review Board Statement: Not applicable.

Informed Consent Statement: Not applicable.

Conflicts of Interest: The authors declare no conflict of interest.

\section{References}

1. Osellame, L.D.; Blacker, T.S.; Duchen, M.R. Cellular and molecular mechanisms of mitochondrial function. Best Pract. Res. Clin. Endocrinol. Metab. 2012, 26, 711-723. [CrossRef]

2. Carreira, R.S.; Billups, P.; Gottlieb, R.A. Mitochondrial therapeutics for cardioprotection. Curr. Pharm. Des. 2011, 17, $2017-2035$. [CrossRef]

3. Chen, H.; Chen, H.; Detmer, S.A.; Ewald, A.J.; Griffin, E.E.; Fraser, S.E.; Chan, D.C. Mitofusins Mfn1 and Mfn2 coordinately regulate mitochondrial fusion and are essential for embryonic devel-opment. J. Cell Biol. 2003, 160, 189-200. [CrossRef] [PubMed]

4. Smirnova, E.; Griparic, L.; Shurland, D.-L.; Van Der Bliek, A.M. Dynamin-related Protein Drp1 Is Required for Mitochondrial Division in Mammalian Cells. Mol. Biol. Cell 2001, 12, 2245-2256. [CrossRef] [PubMed]

5. $\quad$ Labrousse, A.M.; Zappaterra, M.D.; Rube, D.A.; van der Bliek, A.M. C. elegans Dynamin-Related Protein DRP-1 Controls Severing of the Mitochondrial Outer Membrane. Mol. Cell 1999, 4, 815-826. [CrossRef]

6. Lackner, L.L.; Nunnari, J.M. The molecular mechanism and cellular functions of mitochondrial division. Biochim. Biophys. Acta (BBA) Mol. Basis Dis. 2009, 1792, 1138-1144. [CrossRef]

7. Detmer, S.A.; Chan, D.C. Functions and dysfunctions of mitochondrial dynamics. Nat. Rev. Mol. Cell Biol. 2007, 8, 870-879. [CrossRef] [PubMed]

8. Scott, I.; Youle, R.J. Mitochondrial fission and fusion. Essays Biochem. 2010, 47, 85-98. [CrossRef]

9. Chen, Y.; Liu, Y.; Dorn, G.W. Mitochondrial Fusion is Essential for Organelle Function and Cardiac Homeostasis. Circ. Res. 2011, 109, 1327-1331. [CrossRef] 
10. Chen, Y.; Csordás, G.; Jowdy, C.; Schneider, T.G.; Csordás, N.; Wang, W.; Liu, Y.; Kohlhaas, M.; Meiser, M.; Bergem, S.; et al. Mitofusin 2-containing mitochondrial-reticular microdomains direct rapid cardiomyocyte bioenergetic re-sponses via interorganelle $\mathrm{Ca}^{2+}$ crosstalk. Circ. Res. 2012, 111, 863-875. [CrossRef]

11. He, L.; Zhou, Q.; Huang, Z.; Xu, J.; Zhou, H.; Lv, D.; Lu, L.; Huang, S.; Tang, M.; Zhong, J.; et al. PINK1/Parkin-mediated mitophagy promotes apelin-13-induced vascular smooth muscle cell proliferation by AMPKalpha and exacerbates atherosclerotic lesions. J. Cell Physiol. 2019, 234, 8668-8682. [CrossRef]

12. Suen, D.-F.; Narendra, D.P.; Tanaka, A.; Manfredi, G.; Youle, R.J. Parkin overexpression selects against a deleterious mtDNA mutation in heteroplasmic cybrid cells. Proc. Natl. Acad. Sci. USA 2010, 107, 11835-11840. [CrossRef] [PubMed]

13. Narendra, D.; Tanaka, A.; Suen, D.-F.; Youle, R.J. Parkin is recruited selectively to impaired mitochondria and promotes their autophagy. J. Cell Biol. 2008, 183, 795-803. [CrossRef] [PubMed]

14. Sivitz, W.I.; Yorek, M.A. Mitochondrial Dysfunction in Diabetes: From Molecular Mechanisms to Functional Significance and Therapeutic Opportunities. Antioxid. Redox Signal. 2010, 12, 537-577. [CrossRef] [PubMed]

15. Montgomery, M.K.; Turner, N. Mitochondrial dysfunction and insulin resistance: An update. Endocr. Connect. 2015, 4, R1-R15. [CrossRef]

16. Rovira-Llopis, S.; Bañuls, C.; Diaz-Morales, N.; Hernandez-Mijares, A.; Rocha, M.; Victor, V.M. Mitochondrial dynamics in type 2 diabetes: Pathophysiological implications. Redox Biol. 2017, 11, 637-645. [CrossRef] [PubMed]

17. Barot, M.; Gokulgandhi, M.R.; Mitra, A.K. Mitochondrial Dysfunction in Retinal Diseases. Curr. Eye Res. 2011, 36, 1069-1077. [CrossRef] [PubMed]

18. Tang, C.; Dong, Z. Mitochondria in Kidney Injury: When the Power Plant Fails. J. Am. Soc. Nephrol. 2016, $27,1869-1872$. [CrossRef]

19. Lane, M.; Boczonadi, V.; Bachtari, S.; Gomez-Duran, A.; Langer, T.; Griffiths, A.; Kleinle, S.; Dineiger, C.; Abicht, A.; Holinski-Feder, E.; et al. Mitochondrial dysfunction in liver failure requiring transplantation. J. Inherit. Metab. Dis. 2016, 39, 427-436. [CrossRef]

20. Billups, B.; Forsythe, I.D. Presynaptic Mitochondrial Calcium Sequestration Influences Transmission at Mammalian Central Synapses. J. Neurosci. 2002, 22, 5840-5847. [CrossRef] [PubMed]

21. Levy, M.; Faas, G.C.; Saggau, P.; Craigen, W.J.; Sweatt, J.D. Mitochondrial Regulation of Synaptic Plasticity in the Hippocampus. J. Biol. Chem. 2003, 278, 17727-17734. [CrossRef]

22. Liu, J.; Head, E.; Gharib, A.M.; Yuan, W.; Ingersoll, R.T.; Hagen, T.M.; Cotman, C.W.; Ames, B.N. Memory loss in old rats is associated with brain mitochondrial decay and RNA/DNA oxidation: Partial reversal by feeding acetyl-L-carnitine and/or R-lipoic acid. Proc. Natl. Acad. Sci. USA 2002, 99, 2356-2361. [CrossRef]

23. Verstreken, P.; Ly, C.V.; Venken, K.J.; Koh, T.-W.; Zhou, Y.; Bellen, H.J. Synaptic Mitochondria Are Critical for Mobilization of Reserve Pool Vesicles at Drosophila Neuromuscular Junctions. Neuron 2005, 47, 365-378. [CrossRef] [PubMed]

24. Zhao, X.-Y.; Lu, M.-H.; Yuan, D.-J.; Xu, D.-E.; Yao, P.-P.; Ji, W.-L.; Chen, H.; Liu, W.-L.; Yan, C.-X.; Xia, Y.-Y.; et al. Mitochondrial Dysfunction in Neural Injury. Front. Neurosci. 2019, 13, 30. [CrossRef] [PubMed]

25. Zhou, Z.; Austin, G.L.; Young, L.E.A.; Johnson, L.A.; Sun, R. Mitochondrial Metabolism in Major Neurological Diseases. Cells 2018, 7, 229. [CrossRef] [PubMed]

26. de Oliveira, M.R. Vitamin A and Retinoids as Mitochondrial Toxicants. Oxidative Med. Cell. Longev. 2015, 2015, 140267. [CrossRef] [PubMed]

27. Ross, D.A. Recommendations for Vitamin A Supplementation. J. Nutr. 2002, 132, 2902S-2906S. [CrossRef]

28. Tanumihardjo, S.A. Assessing Vitamin A Status: Past, Present and Future. J. Nutr. 2004, 134, 290S-293S. [CrossRef]

29. Allen, L.H.; Haskell, M. Estimating the Potential for Vitamin A Toxicity in Women and Young Children. J. Nutr. 2002, 132, 2907S-2919S. [CrossRef]

30. O'Reilly, K.; Bailey, S.J.; Lane, M.A. Retinoid-Mediated Regulation of Mood: Possible Cellular Mechanisms. Exp. Biol. Med. 2008, 233, 251-258. [CrossRef]

31. National Institute of Health Office of Diary Supplements. Dietary Supplement Fact Sheet-Vitamin A. Vitam. Vitamin A-Health Professional. 2020. Available online: https:/ / ods.od.nih.gov/factsheets/VitaminA-HealthProfessional/ (accessed on 14 February 2020).

32. Kam, R.K.T.; Deng, Y.; Chen, Y.; Zhao, H. Retinoic acid synthesis and functions in early embryonic development. Cell Biosci. 2012, 2, 11. [CrossRef] [PubMed]

33. Davies, W.L.; Hankins, M.W.; Foster, R.G. Vertebrate ancient opsin and melanopsin: Divergent irradiance detectors. Photochem. Photobiol. Sci. 2010, 9, 1444-1457. [CrossRef]

34. Rosselot, C.; Spraggon, L.; Chia, I.; Batourina, E.; Riccio, P.; Lu, B.; Niederreither, K.; Dolle, P.; Duester, G.; Chambon, P.; et al. Non-cell-autonomous retinoid signaling is crucial for renal development. Development 2010, 137, 283-292. [CrossRef] [PubMed]

35. Mallipattu, S.K.; He, J.C. The Beneficial Role of Retinoids in Glomerular Disease. Front. Med. 2015, 2, 16. [CrossRef] [PubMed]

36. Rhinn, M.; Dollé, P. Retinoic acid signaling during development. Development 2012, 139, 843-858. [CrossRef]

37. Duester, G. Retinoic Acid Synthesis and Signaling during Early Organogenesis. Cell 2008, 134, 921-931. [CrossRef]

38. Okumura, L.M.; Okumura, P.C.B.; Veroneze, C. Administration of all-trans retinoic acid through enteral tubes in acute promyelocytic leukemia: The handling of cytotoxic agents and clinical benefits. Rev. Bras. Hematol. Hemoter. 2017, 39, 86-88. [CrossRef]

39. Schmidt, N.; Gans, E.H. Tretinoin: A Review of Its Anti-inflammatory Properties in the Treatment of Acne. J. Clin. Aesthetic Dermatol. 2011, 4, 22-29. 
40. Mukherjee, S.; Date, A.; Patravale, V.; Korting, H.C.; Roeder, A.; Weindl, G. Retinoids in the treatment of skin aging: An overview of clinical efficacy and safety. Clin. Interv. Aging 2006, 1, 327-348. [CrossRef]

41. Tourniaire, F.; Musinovic, H.; Gouranton, E.; Astier, J.; Marcotorchino, J.; Arreguin, A.; Bernot, D.; Palou, A.; Bonet, M.L.; Ribot, J.; et al. All-trans retinoic acid induces oxidative phosphorylation and mitochondria biogenesis in adipocytes. J. Lipid Res. 2015, 56, 1100-1109. [CrossRef]

42. Vantaggiato, C.; Castelli, M.; Giovarelli, M.; Orso, G.; Bassi, M.T.; Clementi, E.; De Palma, C. The Fine Tuning of Drp1-Dependent Mitochondrial Remodeling and Autophagy Controls Neuronal Differentiation. Front. Cell. Neurosci. 2019, 13, 120. [CrossRef]

43. Nan, J.L.; Zhu, W.; Rahman, M.S.; Liu, M.; Li, D.; Su, S.; Zhang, N.; Hu, X.; Yu, H.; Gupta, M.P. Molecular regulation of mitochondrial dynamics in cardiac disease. Biochim. Biophys. Acta-Mol. Cell Res. 2017, 1864, 1260-1273. [CrossRef] [PubMed]

44. Chen, H.; Chan, D.C. Physiological functions of mitochondrial fusion. Ann. N. Y. Acad. Sci. 2010, 1201, 21-25. [CrossRef] [PubMed]

45. Chen, L.; Gong, Q.; Stice, J.P.; Knowlton, A.A. Mitochondrial OPA1, apoptosis, and heart failure. Cardiovasc. Res. 2009, 84, 91-99. [CrossRef] [PubMed]

46. Papanicolaou, K.N.; Khairallah, R.J.; Ngoh, G.A.; Chikando, A.; Luptak, I.; O’Shea, K.M.; Riley, D.D.; Lugus, J.J.; Colucci, W.S.; Lederer, W.J.; et al. Mitofusin-2 Maintains Mitochondrial Structure and Contributes to Stress-Induced Permeability Transition in Cardiac Myocytes. Mol. Cell. Biol. 2011, 31, 1309-1328. [CrossRef] [PubMed]

47. Tandler, B.; Hoppel, C.L. Possible division of cardiac mitochondria. Anat. Rec. Adv. Integr. Anat. Evol. Biol. 1972, 173, 309-323. [CrossRef] [PubMed]

48. Marín-García, J.; Akhmedov, A.T. Mitochondrial dynamics and cell death in heart failure. Heart Fail. Rev. 2016, 21, 123-136. [CrossRef]

49. Song, M.; Franco, A.; Fleischer, J.A.; Zhang, L.; Dorn, G.W. Abrogating Mitochondrial Dynamics in Mouse Hearts Accelerates Mitochondrial Senescence. Cell Metab. 2017, 26, 872-883.e5. [CrossRef]

50. Kuzmicic, J.; del Campo, A.; López-Crisosto, C.; Morales, P.E.; Pennanen, C.; Bravo-Sagua, R.; Hechenleitner, J.; Zepeda, R.; Castro, P.F.; Verdejo, H.E.; et al. Mitochondrial Dynamics: A Potential New Therapeutic Target for Heart Failure. Rev. Española Cardiol. 2011, 64, 916-923. [CrossRef]

51. Claycomb, W.C.; Lanson, N.A.; Stallworth, B.S.; Egeland, D.B.; Delcarpio, J.B.; Bahinski, A.; Izzo, N.J. HL-1 cells: A cardiac muscle cell line that contracts and retains phenotypic characteristics of the adult cardiomyocyte. Proc. Natl. Acad. Sci. USA 1998, 95, 2979-2984. [CrossRef]

52. White, S.M.; Constantin, P.E.; Claycomb, W.C. Cardiac physiology at the cellular level: Use of cultured HL-1 cardio-myocytes for studies of cardiac muscle cell structure and function. Am. J. Physiol. Heart Circ. Physiol. 2004, 286, H823-H829. [CrossRef]

53. Singh, H.; Lu, R.; Rodríguez, P.F.G.; Wu, Y.; Bopassa, J.C.; Stefani, E.; Toro, L. Visualization and quantification of cardiac mitochondrial protein clusters with STED microscopy. Mitochondrion 2012, 12, 230-236. [CrossRef] [PubMed]

54. Graham, J.M. Purification of a Crude Mitochondrial Fraction by Density-Gradient Centrifugation. Curr. Protoc. Cell Biol. 1999, 4, 3.4.1-3.4.22. [CrossRef] [PubMed]

55. Trigo, D.; Goncalves, M.B.; Corcoran, J.P.T. The regulation of mitochondrial dynamics in neurite outgrowth by retinoic acid receptor $\beta$ signaling. FASEB J. 2019, 33, 7225-7235. [CrossRef] [PubMed]

56. Valentijn, J.A.; van Weeren, L.; Ultee, A.; Koster, A.J. Novel localization of Rab3D in rat intestinal goblet cells and Brunner's gland acinar cells suggests a role in early Golgi trafficking. Am. J. Physiol.-Gastrointest. Liver Physiol. 2007, 293, G165-G177. [CrossRef]

57. Ranson, N.; Veldhuis, M.; Mitchell, B.; Fanning, S.; Cook, A.L.; Kunde, D.; Eri, R. NLRP3-Dependent and -Independent Processing of Interleukin (IL)-1 $\beta$ in Active Ulcerative Colitis. Int. J. Mol. Sci. 2018, 20, 57. [CrossRef]

58. Manders, E.M.M.; Verbeek, F.J.; Aten, J.A. Measurement of co-localization of objects in dual-colour confocal images. J. Microsc. 1993, 169, 375-382. [CrossRef] [PubMed]

59. Zamponi, N.; Zamponi, E.; Cannas, S.A.; Billoni, O.V.; Helguera, P.R.; Chialvo, D.R. Mitochondrial network complexity emerges from fission/fusion dynamics. Sci. Rep. 2018, 8, 363. [CrossRef]

60. Shah, S.I.; Paine, J.G.; Perez, C.; Ullah, G. Mitochondrial fragmentation and network architecture in degenerative diseases. PLoS ONE 2019, 14, e0223014. [CrossRef]

61. Sukhorukov, V.M.; Dikov, D.; Reichert, A.S.; Meyer-Hermann, M. Emergence of the Mitochondrial Reticulum from Fission and Fusion Dynamics. PLoS Comput. Biol. 2012, 8, e1002745. [CrossRef]

62. Graham, L.; Orenstein, J.M. Processing tissue and cells for transmission electron microscopy in diagnostic pathology and research Nat. Protoc. 2007, 2, 2439-2450. [CrossRef]

63. Demeter-Haludka, V.; Kovács, M.; Petrus, A.; Patai, R.; Muntean, D.M.; Siklós, L.; Végh, Á. Examination of the Role of Mitochondrial Morphology and Function in the Cardioprotective Effect of Sodium Nitrite Administered $24 \mathrm{~h}$ Before Ischemia/Reperfusion Injury. Front. Pharmacol. 2018, 9, 286. [CrossRef]

64. Kalkhoran, S.B.; Munro, P.; Qiao, F.; Ong, S.-B.; Hall, A.R.; Cabrera-Fuentes, H.; Chakraborty, B.; Boisvert, W.A.; Yellon, D.M.; Hausenloy, D.J. Unique morphological characteristics of mitochondrial subtypes in the heart: The effect of ischemia and ischemic preconditioning. Discoveries 2017, 5, e71. [CrossRef]

65. Verma, A.K.; Rice, H.M.; Shapas, B.G.; Boutwell, R.K. Inhibition of 12-O-Tetradecanoylphorbol-13-acetate-induced Ornithine Decarboxylase Activity in Mouse Epidermis by Vitamin A Analogs (Retinoids). Cancer Res. 1978, $38,793$. 
66. Jansz, A.; Flad, H.D.; Koffler, D.; Miescher, P.A. The Effect of Vitamin A on Experimental Immune Thyroiditis. Int. Arch. Allergy 1967, 31, 69-77. [CrossRef]

67. Strack, S.; Cribbs, J.T. Allosteric Modulation of Drp1 Mechanoenzyme Assembly and Mitochondrial Fission by the Variable Domain*. J. Biol. Chem. 2012, 287, 10990-11001. [CrossRef]

68. Szalkai, B.; Varga, B.; Grolmusz, V. Comparing advanced graph-theoretical parameters of the connectomes of the lobes of the human brain. Cogn. Neurodyn. 2018, 12, 549-559. [CrossRef] [PubMed]

69. Schnakenberg, J. Network theory of microscopic and macroscopic behavior of master equation systems. Rev. Mod. Phys. 1976, 48, 571-585. [CrossRef]

70. Hoffecker, I.T.; Yang, Y.; Bernardinelli, G.; Orponen, P.; Högberg, B. A computational framework for DNA sequencing microscopy. Proc. Natl. Acad. Sci. USA 2019, 116, 19282-19287. [CrossRef]

71. Rohani, A.; Kashatus, J.A.; Sessions, D.T.; Sharmin, S.; Kashatus, D.F. Mito Hacker: A set of tools to enable high-throughput analysis of mitochondrial network morphology. Sci. Rep. 2020, 10, 18941. [CrossRef]

72. Valente, A.J.; Maddalena, L.A.; Robb, E.L.; Moradi, F.; Stuart, J.A. A simple ImageJ macro tool for analyzing mitochondrial network morphology in mammalian cell culture. Acta Histochem. 2017, 119, 315-326. [CrossRef] [PubMed]

73. Liesa, M.; Shirihai, O.S. Mitochondrial Dynamics in the Regulation of Nutrient Utilization and Energy Expenditure. Cell Metab. 2013, 17, 491-506. [CrossRef] [PubMed]

74. Hall, A.R.; Burke, N.; Dongworth, R.K.; Hausenloy, D.J. Mitochondrial fusion and fission proteins: Novel therapeutic targets for combating cardiovascular disease. Br. J. Pharmacol. 2014, 171, 1890-1906. [CrossRef]

75. Suárez-Rivero, J.M.; Villanueva-Paz, M.; De La Cruz-Ojeda, P.; De La Mata, M.; Cotán, D.; Oropesa-Ávila, M.; De Lavera, I.; Álvarez-Córdoba, M.; Luzón-Hidalgo, R.; Sánchez-Alcázar, J.A. Mitochondrial Dynamics in Mitochondrial Diseases. Diseases 2016, 5, 1. [CrossRef]

76. Sabouny, R.; Shutt, T.E. Reciprocal Regulation of Mitochondrial Fission and Fusion. Trends Biochem. Sci. 2020, 45, 564-577. [CrossRef]

77. Martin, O.J.; Lai, L.; Soundarapandian, M.M.; Leone, T.C.; Zorzano, A.; Keller, M.P.; Attie, A.D.; Muoio, D.M.; Kelly, D.P. A role for peroxisome proliferator-activated receptor $\gamma$ coactivator-1 in the control of mitochondrial dy-namics during postnatal cardiac growth. Circ. Res. 2014, 114, 626-636. [CrossRef]

78. Choudhary, V.; Kaddour-Djebbar, I.; Lakshmikanthan, V.; Ghazaly, T.; Thangjam, G.S.; Sreekumar, A.; Lewis, R.W.; Mills, I.G.; Bollag, W.B.; Kumar, M.V. Novel Role of Androgens in Mitochondrial Fission and Apoptosis. Mol. Cancer Res. $2011,9,1067-1077$. [CrossRef]

79. Richter, V.; Singh, A.P.; Kvansakul, M.; Ryan, M.T.; Osellame, L.D. Splitting up the powerhouse: Structural insights into the mechanism of mitochondrial fission. Cell. Mol. Life Sci. 2015, 72, 3695-3707. [CrossRef] [PubMed]

80. Kageyama, Y.; Zhang, Z.; Sesaki, H. Mitochondrial division: Molecular machinery and physiological functions. Curr. Opin. Cell Biol. 2011, 23, 427-434. [CrossRef]

81. Hoppins, S.; Nunnari, J. Mitochondrial Dynamics and Apoptosis-The ER Connection. Science 2012, 337, 1052-1054. [CrossRef]

82. Twig, G.; Elorza, A.; Molina, A.A.J.; Mohamed, H.; Wikstrom, J.D.; Walzer, G.; Stiles, L.; Haigh, S.E.; Katz, S.; Las, G.; et al. Fission and selective fusion govern mitochondrial segregation and elimination by autophagy. EMBO J. 2008, 27, 433-446. [CrossRef] [PubMed]

83. Wu, N.N.; Zhang, Y.; Ren, J. Mitophagy, Mitochondrial Dynamics, and Homeostasis in Cardiovascular Aging. Oxidative Med. Cell. Longev. 2019, 2019, 9825061. [CrossRef]

84. Ferreira-da-Silva, A.; Valacca, C.; Rios, E.; Pópulo, H.; Soares, P.; Sobrinho-Simões, M.; Scorrano, L.; Máximo, V.; Campello, S. Mitochondrial dynamics protein Drp1 is overexpressed in oncocytic thyroid tumors and regulates cancer cell migration. PLoS ONE 2015, 10, e0122308. [CrossRef] [PubMed]

85. Giovarelli, M.; Zecchini, S.; Martini, E.; Garrè, M.; Barozzi, S.; Ripolone, M.; Napoli, L.; Coazzoli, M.; Vantaggiato, C.; Roux-Biejat, P.; et al. Drp1 overexpression induces desmin disassembling and drives kinesin-1 activation promoting mitochonrial trafficking in skeletal muscle. Cell Death Differ. 2020, 27, 2383-2401. [CrossRef]

86. Touvier, T.; De Palma, C.; Rigamonti, E.; Scagliola, A.; Incerti, E.; Mazelin, L.; Thomas, J.-L.; D'Antonio, M.; Politi, L.S.; Schaeffer, L.; et al. Muscle-specific Drp1 overexpression impairs skeletal muscle growth via translational attenuation. Cell Death Dis. 2015, 6, e1663. [CrossRef] [PubMed]

87. Szabadkai, G.; Simoni, A.M.; Chami, M.; Wieckowski, M.R.; Youle, R.J.; Rizzuto, R. Drp-1-Dependent Division of the Mitochondrial Network Blocks Intraorganellar $\mathrm{Ca}^{2+}$ Waves and Pro-tects against $\mathrm{Ca}^{2+}$-Mediated Apoptosis. Mol. Cell 2004, 16, 59-68. [CrossRef]

88. Benard, G.; Bellance, N.; James, D.; Parrone, P.; Fernandez, H.; Letellier, T.; Rossignol, R. Mitochondrial bioenergetics and structural network organization. J. Cell Sci. 2007, 120, 838-848. [CrossRef] [PubMed]

89. Ikeda, Y.; Shirakabe, A.; Maejima, Y.; Zhai, P.; Sciarretta, S.; Toli, J.; Nomura, M.; Mihara, K.; Egashira, K.; Ohishi, M.; et al. Endogenous Drp1 Mediates Mitochondrial Autophagy and Protects the Heart against Energy Stress. Circ. Res. 2015, 116, 264-278. [CrossRef]

90. Fan, H.; He, Z.; Huang, H.; Zhuang, H.; Liu, H.; Liu, X.; Yang, S.; He, P.; Yang, H.; Feng, D. Mitochondrial Quality Control in Cardiomyocytes: A Critical Role in the Progression of Cardiovascular Diseases. Front. Physiol. 2020, 11, 252. [CrossRef] [PubMed] 
91. Ong, S.-B.; Subrayan, S.; Lim, S.Y.; Yellon, D.M.; Davidson, S.M.; Hausenloy, D.J. Inhibiting Mitochondrial Fission Protects the Heart against Ischemia/Reperfusion Injury. Circulation 2010, 121, 2012-2022. [CrossRef]

92. Ashrafian, H.; Docherty, L.; Leo, V.; Towlson, C.; Neilan, M.; Steeples, V.; Lygate, C.A.; Hough, T.; Townsend, S.; Williams, D.; et al. A Mutation in the Mitochondrial Fission Gene Dnm11 Leads to Cardiomyopathy. PLoS Genet. 2010, 6, e1001000. [CrossRef]

93. Tang, Y.; Mi, C.; Liu, J.; Gao, F.; Long, J. Compromised mitochondrial remodeling in compensatory hypertrophied myocardium of spontaneously hy-pertensive rat. Cardiovasc. Pathol. 2014, 23, 101-106. [CrossRef]

94. Pennanen, C.; Parra, V.; López-Crisosto, C.; Morales, P.E.; Del Campo, A.; Gutierrez, T.; Rivera-Mejías, P.; Kuzmicic, J.; Chiong, M.; Zorzano, A.; et al. Mitochondrial fission is required for cardiomyocyte hypertrophy mediated by a $\mathrm{Ca}^{2+}$-calcineurin signal-ing pathway. J. Cell Sci. 2014, 127 Pt 12, 2659-2671. [CrossRef]

95. Kageyama, Y.; Hoshijima, M.; Seo, K.; Bedja, D.; Sysa-Shah, P.; Andrabi, S.A.; Chen, W.; Höke, A.; Dawson, V.L.; Dawson, T.M.; et al. Parkin-independent mitophagy requires Drp1 and maintains the integrity of mammalian heart and brain. EMBO J. 2014, 33, 2798-2813. [CrossRef]

96. Sharp, W.W.; Fang, Y.H.; Han, M.; Zhang, H.J.; Hong, Z.; Banathy, A.; Morrow, E.; Ryan, J.J.; Archer, S.L. Dynamin-related protein 1 (Drp1)-mediated diastolic dysfunction in myocardial ischemia-reperfusion injury: Therapeutic benefits of Drp1 inhibition to reduce mitochondrial fission. FASEB J. 2014, 28, 316-326. [CrossRef] [PubMed]

97. Song, M.; Mihara, K.; Chen, Y.; Scorrano, L.; Dorn, G.W., II. Mitochondrial fission and fusion factors reciprocally orchestrate mitophagic culling in mouse hearts and cul-tured fibroblasts. Cell Metab. 2015, 21, 273-286. [CrossRef] [PubMed]

98. Qiu, J.; Huang, Y.; Chen, G.; Chen, Z.; Tweardy, D.J.; Dong, S. Aberrant Chromatin Remodeling by Retinoic Acid Receptor $\alpha$ Fusion Proteins Assessed at the Single-Cell Level. Mol. Biol. Cell 2007, 18, 3941-3951. [CrossRef] [PubMed]

99. Frezza, C.; Cipolat, S.; De Brito, O.M.; Micaroni, M.; Beznoussenko, G.V.; Rudka, T.; Bartoli, D.; Polishuck, R.S.; Danial, N.N.; De Strooper, B.; et al. OPA1 Controls Apoptotic Cristae Remodeling Independently from Mitochondrial Fusion. Cell 2006, 126, 177-189. [CrossRef] [PubMed]

100. Olichon, A.; Baricault, L.; Gas, N.; Guillou, E.; Valette, A.; Belenguer, P.; Lenaers, G. Loss of OPA1 Perturbates the Mitochondrial Inner Membrane Structure and Integrity, Leading to Cytochrome c Release and Apoptosis. J. Biol. Chem. 2003, 278, 7743-7746. [CrossRef] [PubMed] 